\title{
Momentum search algorithm: a new meta-heuristic optimization algorithm inspired by momentum conservation law
}

\author{
Mohammad Dehghani $^{1}$ (I) Haidar Samet ${ }^{1}$ (i)
}

Received: 10 February 2020 / Accepted: 15 September 2020 / Published online: 23 September 2020

(c) Springer Nature Switzerland AG 2020

\begin{abstract}
A novel optimization methodology, Momentum Search Algorithm (MSA) is presented based on Newton's laws: the law of conservation of momentum. It includes a set of masses in a closed system considering the conservation of momentum and kinetic energy of bodies. The possible solutions are presented by system bodies' positions in an $n$-dimensional space. The mass of bodies is proportional to their fitness function. Larger masses represent the better solutions. At each iteration, an external body collides separately with all solution bodies and moves them toward the optimum solution. The direction of the collision depends on the position of solution bodies and the position of the body with the best fitness function. As the better solutions have heavier bodies, the external body has less effect on their positions. On the other hand, the worse solutions are lighter and moved easily by the external body toward the better positions. The best position is achieved by allowing the external body to move the solution bodies toward better positions. The numerical results obtained from several standard benchmark test functions indicate the superiority of the proposed method over many other optimization techniques such as Genetic Algorithm, Particle Swarm Optimization, Gravitational Search Algorithm, Teaching-Learning-Based Optimization, Grey Wolf Optimizer, Grasshopper Optimization Algorithm, Spotted Hyena Optimizer, and Emperor Penguin Optimizer.
\end{abstract}

Keywords Optimization · Heuristic optimization algorithms · Momentum search algorithm · Law of conservation of momentum

\section{List of symbols}

$m \quad$ The mass of bodies

M The mass of external body

$\alpha \quad$ The acceleration of the bodies

$v \quad$ The speed of the bodies before collision

$V \quad$ The speed of the bodies after collision

$P \quad$ The momentum of the bodies

$F \quad$ The total force on a body

$n \quad$ The number of dimensions

$j \quad$ Index for the number of dimensions

$i \quad$ Index for the number of bodies

$r_{1}, r_{2} \quad$ Random numbers in the range of $[0-1]$

$t \quad$ Time index

$T \quad$ The maximum number of iterations
$U_{\max } \quad$ The maximum speed of external body

$X_{i}(t) \quad$ The position of $i$ th body at time $t$

$x_{i}^{(d)}(t) \quad$ The position of ith body at time $t$ which is in line with $d$ th dimension

$x_{\min ^{\prime}}^{(j)} x_{\max }^{(j)} \quad$ The minimum and maximum values for the position of bodies in $j$ th dimension

\section{Introduction}

Nowadays, considering progressive increase in dimension of real-world optimization problems and the importance of fast finding of global optima, traditional algorithms such as LP, NLP, DP are less attractive to researchers. This

Mohammad Dehghani, adanbax@gmail.com; Haidar Samet, samet@shirazu.ac.ir| ${ }^{1}$ School of Electrical and Computer Engineering, Shiraz University, Shiraz, Iran. 
is due to the significant losses in LP when a linear model is extracted from a nonlinear one, and the fact that NLP cannot find optima in the presence of non-differentiable functions [1]. Moreover, computational burden and the required time and memory in DP would exponentially increase by an increase in the number of control variables. Furthermore, selecting initial values for control variables results in high sensitivity for reaching global optima [2]. Instead, heuristic optimization algorithms, which are based on nature rules, are being used extensively to overcome the shortcomings of traditional techniques. Using heuristic approaches, a near-optimum solution can be found within an acceptable computation time and memory without considering suitable initial values for control variables, the differentiability of functions and their nonlinear characteristics [3].

So far, many evolutionary algorithms have been developed based on randomness of natural phenomena. These phenomena encompass various natural processes such as animal behavior (e.g., Donkey Theorem Optimization (DTO) [4], Honey Bees Mating (HBM) [5], Shuffled Frog Leaping Algorithm (SFLA) [6], Hunting Search (HS) [7], Ant Colony Optimization (ACO) [8], and Particle Swarm Optimization (PSO) [9]), biological processes (e.g., Genetic Algorithm (GA) [10], Differential Evolution (DE) [11], Evolution Strategy (ES) [12], Genetic Programming (GP) [13], and Biogeography-based Optimizer (BBO) [14], Artificial Immune Systems (AIS) [15]), the physical process (e.g. Spring Search Algorithm (SSA) [16, 17], Simulated Annealing (SA) [18]), the musical process (i.e. Harmony Search (HS) [19-22]), population process (i.e. Following Optimization Algorithm (FOA) [23], Group Optimization (GO) [24]), and the game-based processes (e.g., Dice Game Optimizer (DGO) [25, 26], Orientation Search Algorithm (OSA) [27, 28], and Shell Game Optimization (SGO) [29]). In addition, some other algorithms are proposed during recent years such as Gravitational Search Algorithm (GSA) [30], Magnetic Particle Swarm Optimization (MPSO) [31], Teaching-Learning-Based Optimization (TLBO) [32], Artificial Bee Colony (ABC) [33], Grey Wolf Optimizer (GWO) [34], Colliding Bodies Optimization (CBO) [35], BI-Population CMA-ES (BiPOP-CMA-ES) [36], Moth Search Algorithm (MSA) [37, 38], Monarch Butterfly Optimization (MBO) [39, 40], Earthworm Optimization Algorithm (EWA) [41], and Elephant Herding Optimization (EHO) [42, 43].

The search technique in HBM process is based on the process of honey bees mating. SFLA imitates the natural phenomenon that is based on the populations of frogs searching for food. HuS has been inspired by a group of hunting animals looking for a prey in a group. ACO algorithm is based on the behavior of ants seeking an optimum path between their colony and a source of food. PSO was proposed based on research on swarms such as fish schooling and bird flocking. GA is another global search algorithm inspired by the concepts of natural genetics and Darwinian survival-of-the-fittest code. SA is a generalization of the Monte Carlo simulation and is used for examining the state equations and frozen states for an $n$-body system. This concept is inspired by the style in which liquids freeze or metals recrystallize in an annealing process. HS conceptualized by the musical process of searching for a perfect state of harmony is a meta-heuristic algorithm and is used to find global optima. In GSA [30], the population is a collection of masses which interact based on the Newtonian gravity. The particle swarm method proposed in MPSO [31] is based on the idea of repulsion by a magnetic field. The influence of a teacher on learners is utilized in TLBO [32]. ABC Algorithm is based on the intelligent behavior of honey bee swarm [33]. GWO algorithm utilizes the leadership hierarchy and hunting mechanism of grey wolves [34]. CBO is based on collisions between system bodies, where the worse system bodies collide with the better ones and update their current positions [35]. In [36] BiPOP-CMA-ES is proposed which is a Multi-start CMA-ES with equal budgets for two interlaced restart strategies. In addition, many improved methods for optimization algorithms are introduced in [44-50].

Unlike traditional optimization methods, most of the heuristic algorithms search the space of problem in a parallel manner with many initial points, e.g. swarm-based algorithms inspired by animals' behavior. In addition, these algorithms do not use the information of space gradient; instead, they use fitness functions to search the space. The optima are found by the aid of the swarm intelligence. The group members in a swarm-based algorithm have positive feedback, negative feedback, and some rule-based interactions with a random manner with each other. Thus, they provide a self-organized system [51]. These algorithms have shown their high abilities to solve optimization problems in different sciences such as medical [52], energy [53, 54], power engineering [55-57], protection [58], and energy carriers [59,60]. Even though many works have been done on these heuristic algorithms, more powerful ones are required to solve complex real-world optimization problems.

The proposed optimization algorithm in this paper, Momentum Search Algorithm (MSA), is based on two important physics' laws: momentum conservation law and kinetic energy conservation law [61]. It includes a set of bodies called solution bodies in a closed system considering the conservation of momentum and kinetic energy of masses. The bodies' $n$-dimensional position represents the possible solutions at every iteration. The mass of solution bodies reflects their fitness value so heavier bodies are associated with better solutions. The idea is simple but effective. At each iteration, an external body collides 
separately with all solution bodies and moves them in a random direction which is not in reverse with the direction toward the iteration's best solution. The better solutions, which have heavier masses, are moving slower than the worse solutions which are lighter. The mass and the speed of the external body are reduced during each iteration. In this way the algorithm preserves two important concepts in the heuristic algorithms: exploration and exploitation. The ability of searching broadly the space is named exploration while the exploitation is the ability of finding the optima approximately.

In most of heuristic algorithms, the entire population agents affect each other. However, in the proposed MSA, there is only one force on each agent at every iteration. Such force stems from colliding external body separately to all agents. This fact, in comparison with, other techniques approved numerically in the last section reduce the complexity and computation load of the algorithm significantly.

The efficiency of the proposed MSA is evaluated through several standard benchmark test functions. Moreover, in order to have a fair comparison, many other optimization techniques such as GA, PSO, GSA, TLBO, GWO, $\mathrm{GOA}, \mathrm{SHO}$, and EPO are tested on the same datasets.

This paper is organized as follows. In Sect. 2, two fundamental laws of physics related to the proposed method are described. In Sect. 3, the framework of the proposed method beside its optimization algorithm is presented. In Sect. 4, different test cases are applied to compare the performance of the proposed algorithm with the mentioned optimization algorithms. Finally in Sect. 5, conclusion and future work are presented.

\section{Momentum conservation law}

Momentum is a concept for an object with mass $m$ and speed $v$. It is shown by $P$ and defined as follows [61]:
$P=m v$

Equation (1) shows every object will have a controllable momentum which is proportional to the mass $m$ and speed $v$. Newton's motion laws are the fundamental laws of physics. He showed the importance of momentum law as a physical concept by a new expression of his second law. His second law states that the net force on a constant mass is equal to its momentum rate of change. Since Newton's second law is valid for bodies with constant mass, the new form of Newton's second law can be presented as follows.

$F=m \alpha=m \frac{d v}{d t}=\frac{d(m v)}{t}=\frac{d P}{d t}$

where $\alpha$ is the acceleration of the body.

Furthermore, consistent with Newton's first law, which states that the net force on a body with a constant speed is equal to zero, the momentum of a body will not change when the net force on it is zero. This concept is known as momentum conservation law and can be developed for a closed system including many bodies. According to Fig. 1a, suppose a closed system with two spherical bodies with mass $m_{1}$ and $m_{2}$ which move in a direction with speeds $v_{1}$ and $v_{2}$. In Fig. $1 \mathrm{~b}$ at the moment of collision according to Newton's third law, $F_{1}$ and $F_{2}$ are two equal forces with opposite directions. Their speed after a collision will be $V_{1}$ and $V_{2}$.

Since the system is supposed to be a closed one, according to momentum conservation law, the momentum of the system before collision is equal to the momentum of system after collision.

$m_{1} v_{1}+m_{2} v_{2}=m_{1} v_{1}+m_{2} v_{2}$

If the collision is supposed to be an elastic one, then the conservation of kinetic energy of the system will be valid as shown by (4).
Fig. 1 The collision of two bodies, (a) before collision, (b) at the moment of collision, (c) after collision

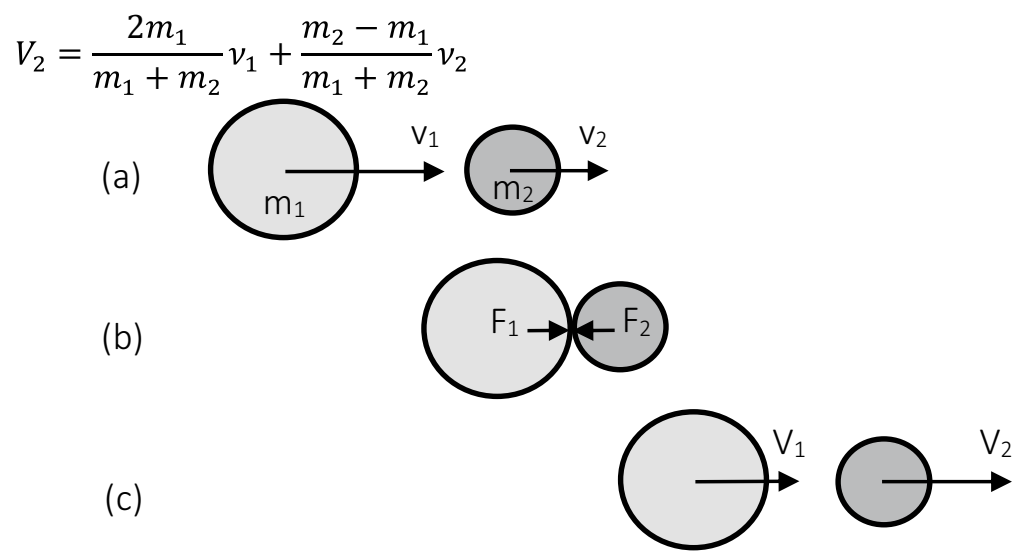

SN Applied Sciences

a SPRINGER NATURE journal 
$\frac{1}{2} m_{1} v_{1}^{2}+\frac{1}{2} m_{2} v_{2}^{2}=\frac{1}{2} m_{1} V_{1}^{2}+\frac{1}{2} m_{2} V_{2}^{2}$

After some mathematical simplifications of (3) and (4), we have following expressions.

$m_{1}\left(v_{1}-V_{1}\right)=m_{2}\left(v_{2}-v_{2}\right)$

$m_{1}\left(v_{1}^{2}-V_{1}^{2}\right)=m_{2}\left(V_{2}^{2}-v_{2}^{2}\right)$

By dividing Eq. (6) by (5), the relationship between the speeds of two bodies can be written as (7).

$v_{1}+v_{1}=v_{2}+v_{2}$

Considering Eqs. (3) and (7), the speed of bodies after an elastic collision can be calculated as follows:

$v_{1}=\frac{m_{1}-m_{2}}{m_{1}+m_{2}} v_{1}+\frac{2 m_{2}}{m_{1}+m_{2}} v_{2}$
$v_{2}=\frac{2 m_{1}}{m_{1}+m_{2}} v_{1}+\frac{m_{2}-m_{1}}{m_{1}+m_{2}} v_{2}$

\section{Momentum search algorithm}

In this paper, the optimization process is done in an artificial and time-discrete using momentum and motion laws. The problem constraints are the borders of the system. The utilized system consists of a set of solution bodies, which their position in a space with $n$ dimensions represents the possible solutions. The mass of bodies is proportional to their fitness function which is in relation with their position. Hence the bodies in better positions (solutions) have more mass, and it is harder to move them from the present position than the lighter bodies which represent smaller fitness function.

At each iteration, an external body collides separately with all solution bodies and moves them by the average toward the heaviest body. The direction of the collision depends of the position of solution bodies and the position of the body which have the best fitness function at that iteration.

The MSA algorithm has three general steps. Step 1: forming an artificial time-discrete and closed system and positioning for all bodies considering constraints of the problem. Step 2: implementing motion and conservation laws. Step 3: letting time to pass in discrete steps until a criterion is met.

\subsection{Step 1}

In the first step, an artificial time-discrete and closed system is considered to form a specified space for placing a limited number of bodies. This space includes an $n$-dimensional coordinate system in which each point can be a solution of the problem. The search agents in this space are a set of bodies with different masses which seek diverse positions in the space to reach the optimum position from the initial position.

Now, suppose the defined system encompasses $m$ motionless bodies with predetermined initial positions which are initial solutions of the problem. In (10), the position of ith body in time $t$ is shown by $X_{i}(t)$. For this body, the position which is in line with $d$ th dimension is shown by $x_{i}^{(d)}(t)$.

$$
\begin{gathered}
x_{i}(t)=\left(x_{i}^{(1)}(t), \ldots, x_{i}^{(d)}(t), \ldots, x_{i}^{(n)}(t)\right), \\
x_{\text {min }}^{(j)} \leq x_{i}^{(j)}(t) \leq x_{\text {max }}^{(j)} i=1, \ldots, m,
\end{gathered}
$$

$j=1, \ldots, n$

\subsection{Step 2}

\subsubsection{A: updating the mass of the solution bodies}

Better solutions have more mass, while the worse solutions have less mass which cause them to move toward the better solutions. At the beginning of each iteration, the following equation is used to calculate the mass of bodies. This formula is based on the assumption that the best answer has the minimum fitness function.

$m_{i}(t)=\frac{f i t_{i}(t)-\operatorname{worst}(t)}{\operatorname{best}(t)-\operatorname{worst}(t)}$

where $f t_{i}(t)$ is the value of objective function for $X_{i}(t)$. Using (11) more mass is allocated to the bodies with high suitability to reach the optimum point. The value of best $(t)$ and worst $(t)$ is calculated by (12) and (13).

$\operatorname{best}(t)=\min _{i=1, \ldots, m} f i t_{i}(t)$

$\operatorname{worst}(t)=\max _{i=1, \ldots, m} f i t_{i}(t)$

In other words, for the bodies with better fitness function, more mass is allocated; consequently, the external body changes the position of each body in reverse to its superiority. The better solutions will move slower than the worse ones. 


\subsubsection{B: the mass and speed of the external body}

It should be noted that there are two important concepts in the swarm-based heuristic algorithms: exploration and exploitation. The ability of widely searching the space is named exploration while the exploitation is the ability of approximately finding the optima. To dictate a high performance to heuristic algorithms, there should be a suitable compromise between exploration and exploitation. Although most of the swarm-based heuristic algorithms use different approaches to provide this compromise, the new technique which is used to improve the performance of MSA to find optimum point fast is the control of external body momentum. In fact, in primary iterations, there is a necessity for the algorithm to vastly search the space with large momentums (i.e., exploration concept), while after some iterations, the momentum of external body should be reduced to increase the accuracy of the search in optimum point surroundings (i.e. exploitation concept) $[62,63]$.

At every iteration, all solution bodies are motionless, and there is a separate external body in the space called external body. Such body collides with all other bodies and changes their positions toward better ones. Since we know by the passage of time, all bodies approach to the sub-optimum point, it is essential for bodies to search the space with smaller and more accurate steps. In order to achieve this task, the mass and velocity of external body decrease in time with the maximum mass of unity for external body. The mass of the external body at iteration $t$ is calculated using Eq. (14):

$M(t)=1-\frac{t-1}{T-1}$

where $T$ is the maximum number of iterations acquired by the algorithm. Using (11), the mass of external body is equal to 1 at the first iteration and then is decreased in a constant rate till reaches zero at the last iteration.

The speed of the external body should also get decreased over time. The direction of the collision should move the system bodies to the sub-optimum point. However, to avoid falling in local optimums, some random terms should be considered in the speed equation of the external body. The speed of external body is a vector whose size is equal to system dimension $(n)$. The value of $d^{\prime}$ th speed component of the external body which collides with $i^{\prime}$ th system body at iteration number $t$ is given in (15):

$U_{i}^{(d)}(t)=r_{1} \cdot\left(1-\frac{t-1}{T-1}\right) \cdot U_{\max } \cdot \operatorname{sign}\left(x_{\text {best }}^{(d)}(t)-x_{i}^{(d)}(t)\right)$
In (15), $r_{1}$ is a random number with a uniform distribution in the range of $[0,1]$ which gives the problem a random performance for seeking the absolute optimum. $U_{\max }$ defined by the limits of the problem control variables is the maximum speed of external body. The term $\left(1-\frac{t-1}{T-1}\right) \cdot U_{\max }$ reveals that despite the existence of the random term, the speed of the external body decreases in average by the time. $x_{\text {best }}^{(d)}(t)$ and $x_{i}^{(d)}(t)$ are the values of $d^{\prime}$ th dimension of the system body with the best fitness for iteration $t$ and $i^{\prime}$ th system body. The term $\operatorname{sign}\left(x_{\text {best }}^{(d)}(t)-x_{i}^{(d)}(t)\right)$ guarantees the system bodies will not move in opposite direction of the best answer. In other words, using sign function instead of $x_{\text {best }}^{(d)}-x_{i}^{(d)}$ indicates that the bodies will not approach the best answer of every iteration precisely. However, they do not move in completely opposite directions.

Consequently, in this method using (14) and (15), we are able to regulate the momentum of external body to improve the performance of MSA. The $d$ 'th component of the external body momentum which collides with $i$ 'th system body at iteration $t$ is given by (16):

$P_{i}^{(d)}(t)=M(t) U_{i}^{(d)}(t)$

\subsubsection{C: calculating the new position of system bodies after collisions}

After collision with $i^{\text {th }}$ body at time $t$, by implementing the momentum and kinetic energy conservation laws (17) and (18), the speed of bodies $\left(V_{i}^{(d)}(t)\right)$ is calculated by (19).

$M(t) U_{i}^{(d)}(t)=m_{i}(t) V_{i}^{(d)}(t)+M(t) u_{i}^{(d)}(t)$

$\frac{1}{2} M(t)\left(U_{i}^{(d)}(t)\right)^{2}=\frac{1}{2} m_{i}(t)\left(V_{i}^{(d)}(t)\right)^{2}+\frac{1}{2} M(t)\left(u_{i}^{(d)}(t)\right)^{2}$

$V_{i}^{(d)}(t)=\frac{2 M(t)}{m_{i}(t)+M(t)} U_{i}^{(d)}(t)$

where, $\mathrm{M}(\mathrm{t}), U_{i}^{(d)}(t)$ and $u_{i}^{(d)}(t)$ are the mass of the external body and its speeds before and after the collision. $m_{i}(t)$ and $V_{i}^{(d)}(t)$ are the mass of $i^{\prime}$ th system body and its $d^{\prime}$ th dimension speed component after the collision.

Using the after collision speed of the system bodies in (16), their new position is attained by (20). It states that the current position of each body is the summation of a percentage of its previous position and a percentage of its speed after collision. 
$x_{i}^{(d)}(t+1)=x_{i}^{(d)}(t)+r_{2} V_{i}^{(d)}(t)$

where, $V_{i}^{(d)}(t)$ is the speed of ith body in direction of $d$ th dimension in time $t$, and $r_{2}$ is a random number with a uniform distribution in the range of $[0,1]$.

\subsection{Step 3}

The algorithm shown in Fig. 2 continues until a predetermined criterion is satisfied. The pseudocode of MSA is shown in Algorithm 1.

Determine the problem parameters: the number of bodies, variables, and the scope of the search

The best and worst body is determined by Equations (12)-(13).

The mass of the external body is updated. Equation (14).

Fig. 2 The flowchart of the proposed MSA
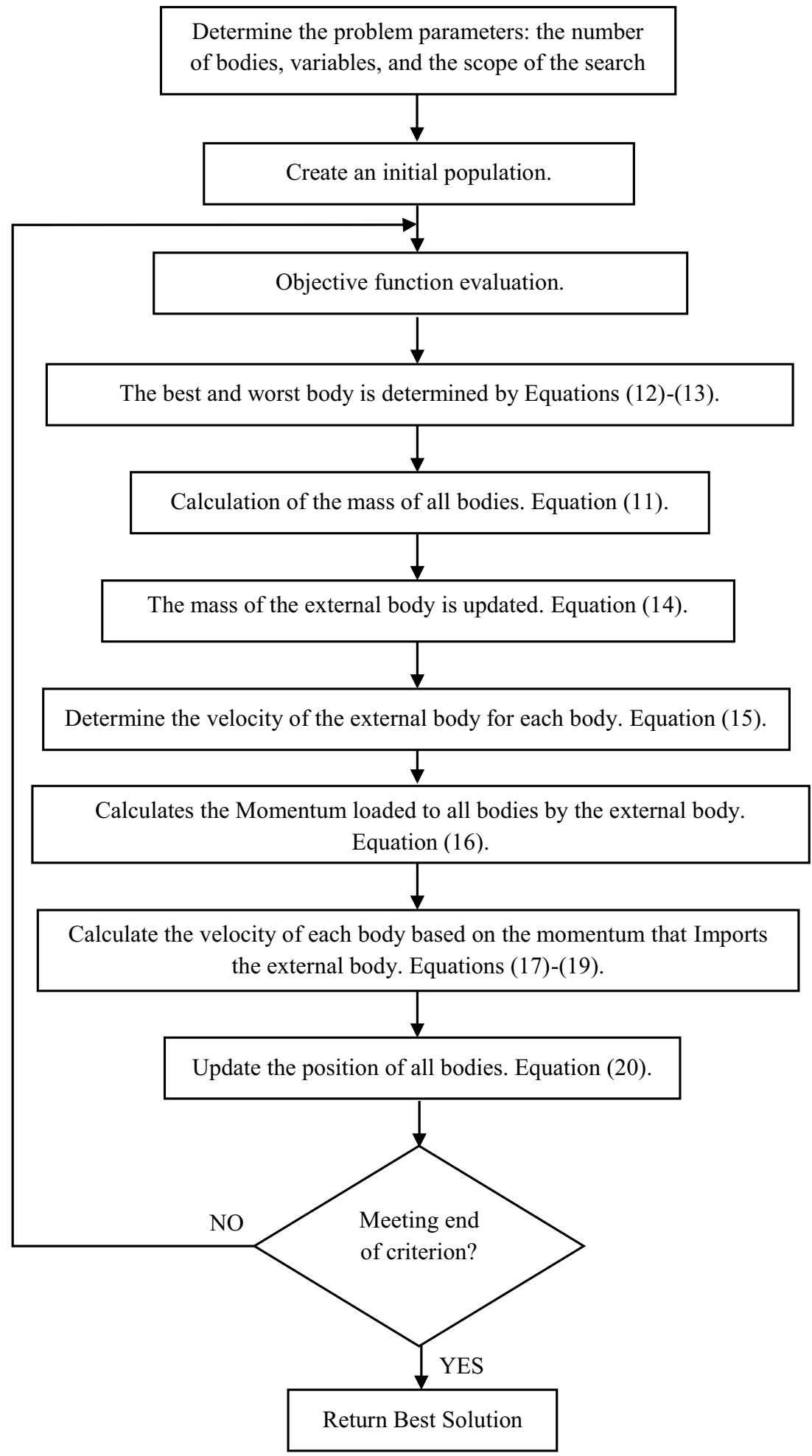


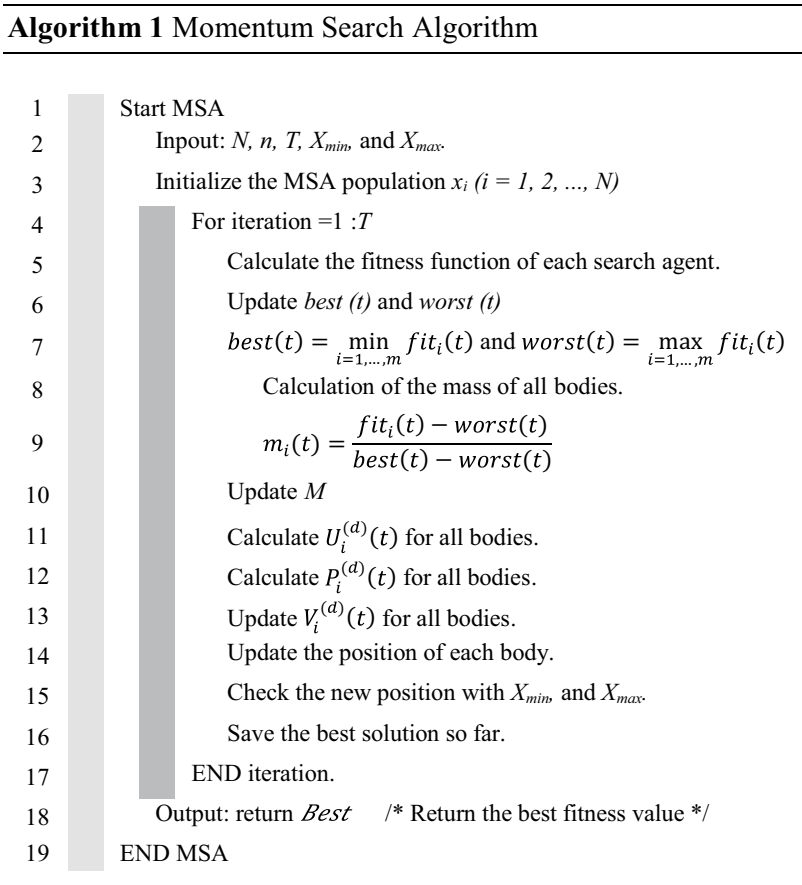

\section{Experimental results and discussion}

The experimentation and simulation of MSA with twentythree standard benchmark test functions is defined in this section. In addition, the results are compared and analyzed with well-known optimization algorithms.

\subsection{Description of benchmark test functions}

The 23 benchmark test functions are used to demonstrate the applicability and efficiency of the proposed algorithm. These functions are divided into three main categories: Unimodal $[64,65]$, Multimodal $[65,66]$, Fixed-dimension Multimodal [65]. The description of these test functions is given in "Appendix".

\subsection{Experimental setup}

Performance of the MSA is compared with the following eight optimization algorithms: Genetic Algorithm (GA) [67], Particle Swarm Optimization (PSO) [68], Gravitational Search Algorithm (GSA) [30], Teaching-Learning-Based Optimization (TLBO) [32], Grey Wolf Optimizer (GWO) [34],
Grasshopper Optimization Algorithm (GOA) [69], Spotted Hyena Optimizer (SHO) [70], and Emperor Penguin Optimizer (EPO) [71]. The experimentation has been done on MATLAB R2017b version using 64 bit Core i7 processor with $3.20 \mathrm{GHz}$ and $16 \mathrm{~GB}$ main memory.

\subsection{Performance comparison}

The performance of MSA is compared with eight mentioned optimization algorithms on unimodal, multimodal, and fixed-dimension multimodal. The average and standard deviation is considered as the best optimal solution on benchmark functions. For benchmark test functions, MSA simulates 30 independent runs in which each run employs 1000 number of iterations.

\subsubsection{Evaluation of test functions $F_{1}-F_{7}$}

The results of implantation of MSA and other algorithms on unimodal test function are shown in Table 1. For $F_{1}, F_{2}$ and $F_{3}, E P O$ is the best optimizer, and MSA, in terms of average and standard deviation, is the second-best optimizer. However, MSA provides better results for other unimodal benchmark test functions. Therefore, MSA presents effective and acceptable results compared to the other eight algorithms.

\subsubsection{Evaluation of test functions $F_{8}-F_{13}$}

Table 2 shows the results of MSA and other mentioned algorithms on multimodal benchmark test functions. This table shows that MSA is able to provide near-optimal solution on four benchmark test functions $\left(F_{8^{\prime}} F_{10}, F_{12}\right.$, and $\left.F_{13}\right)$. EPO provides near-optimal results than MSA on $F_{9}$ and $F_{11}$. MSA is the second-best optimizer on these benchmark test functions. Therefore, MSA presents effective and acceptable results compared to the other eight algorithms.

\subsubsection{Evaluation of test functions $F_{14}-F_{23}$}

Table 3 shows the computational performance of MSA and other algorithms on fixed-dimension multimodal benchmark test functions. Based on this table, MSA is able to find near-optimal solution on six benchmark test functions $\left(F_{14}\right.$ $F_{15}, F_{17}, F_{18}, F_{19}, F_{21}$, and $\left.F_{22}\right)$. For ${ }_{16}$, EPO provides near-optimal results than MSA. MSA is the second-best optimizer on $F_{16}$. For $F_{20}$, PSO and MSA are the first and second-best optimization algorithms, respectively. The results show 
Table 1 Results for MSA and other algorithms on Unimodal test functions

\begin{tabular}{lllllllllll}
\hline & & GA & PSO & GSA & TLBO & GOA & GWO & SHO & EPO & MSA \\
\hline $\mathrm{F}_{1}$ & Ave & $1.95 \mathrm{E}-12$ & $4.98 \mathrm{E}-09$ & $1.16 \mathrm{E}-16$ & $3.55 \mathrm{E}-02$ & $2.81 \mathrm{E}-01$ & $7.86 \mathrm{E}-10$ & $4.61 \mathrm{E}-23$ & $\mathbf{6 . 7 4 E}-\mathbf{3 5}$ & $5.71 \mathrm{E}-28$ \\
& std & $2.01 \mathrm{E}-11$ & $1.40 \mathrm{E}-08$ & $6.10 \mathrm{E}-17$ & $1.06 \mathrm{E}-01$ & $1.11 \mathrm{E}-01$ & $8.11 \mathrm{E}-09$ & $7.37 \mathrm{E}-23$ & $\mathbf{9 . 1 7 E}-\mathbf{3 6}$ & $8.31 \mathrm{E}-29$ \\
$\mathrm{~F}_{2}$ & Ave & $6.53 \mathrm{E}-18$ & $7.29 \mathrm{E}-04$ & $1.70 \mathrm{E}-01$ & $3.23 \mathrm{E}-05$ & $3.96 \mathrm{E}-01$ & $5.99 \mathrm{E}-20$ & $1.20 \mathrm{E}-34$ & $\mathbf{7 . 7 8 E}-\mathbf{4 5}$ & $6.20 \mathrm{E}-40$ \\
& std & $5.10 \mathrm{E}-17$ & $1.84 \mathrm{E}-03$ & $9.29 \mathrm{E}-01$ & $8.57 \mathrm{E}-05$ & $1.41 \mathrm{E}-01$ & $1.11 \mathrm{E}-17$ & $1.30 \mathrm{E}-34$ & $\mathbf{3 . 4 8 E}-\mathbf{4 5}$ & $3.32 \mathrm{E}-40$ \\
$\mathrm{~F}_{3}$ & Ave & $7.70 \mathrm{E}-10$ & $1.40 \mathrm{E}+01$ & $4.16 \mathrm{E}+02$ & $4.91 \mathrm{E}+03$ & $4.31 \mathrm{E}+01$ & $9.19 \mathrm{E}-05$ & $1.00 \mathrm{E}-14$ & $\mathbf{2 . 6 3 E}-\mathbf{2 5}$ & $2.05 \mathrm{E}-19$ \\
& std & $7.36 \mathrm{E}-09$ & $7.13 \mathrm{E}+00$ & $1.56 \mathrm{E}+02$ & $3.89 \mathrm{E}+03$ & $8.97 \mathrm{E}+00$ & $6.16 \mathrm{E}-04$ & $4.10 \mathrm{E}-14$ & $\mathbf{9 . 8 3 E}-\mathbf{2 7}$ & $9.17 \mathrm{E}-20$ \\
$\mathrm{~F}_{4}$ & Ave & $9.17 \mathrm{E}+01$ & $6.00 \mathrm{E}-01$ & $1.12 \mathrm{E}+00$ & $1.87 \mathrm{E}+01$ & $8.80 \mathrm{E}-01$ & $8.73 \mathrm{E}-01$ & $2.02 \mathrm{E}-14$ & $4.32 \mathrm{E}-18$ & $\mathbf{4 . 6 5 E}-\mathbf{2 6}$ \\
& std & $5.67 \mathrm{E}+01$ & $1.72 \mathrm{E}-01$ & $9.89 \mathrm{E}-01$ & $8.21 \mathrm{E}+00$ & $2.50 \mathrm{E}-01$ & $1.19 \mathrm{E}-01$ & $2.43 \mathrm{E}-14$ & $3.98 \mathrm{E}-19$ & $\mathbf{4 . 6 8 E}-\mathbf{2 9}$ \\
$\mathrm{F}_{5}$ & Ave & $5.57 \mathrm{E}+02$ & $4.93 \mathrm{E}+01$ & $3.85 \mathrm{E}+01$ & $7.37 \mathrm{E}+02$ & $1.18 \mathrm{E}+02$ & $8.91 \mathrm{E}+02$ & $2.79 \mathrm{E}+01$ & $5.07 \mathrm{E}+00$ & $\mathbf{5 . 4 1 E}-\mathbf{0 1}$ \\
& std & $4.16 \mathrm{E}+01$ & $3.89 \mathrm{E}+01$ & $3.47 \mathrm{E}+01$ & $1.98 \mathrm{E}+03$ & $1.43 \mathrm{E}+02$ & $2.97 \mathrm{E}+02$ & $1.84 \mathrm{E}+00$ & $4.90 \mathrm{E}-01$ & $\mathbf{5 . 0 5 E}-\mathbf{0 2}$ \\
$\mathrm{F}_{6}$ & Ave & $3.15 \mathrm{E}-01$ & $9.23 \mathrm{E}-09$ & $1.08 \mathrm{E}-16$ & $4.88 \mathrm{E}+00$ & $3.15 \mathrm{E}-01$ & $8.18 \mathrm{E}-17$ & $6.58 \mathrm{E}-01$ & $\mathbf{7 . 0 1 E}-19$ & $\mathbf{8 . 0 3 E}-\mathbf{2 4}$ \\
& std & $9.98 \mathrm{E}-02$ & $1.78 \mathrm{E}-08$ & $4.00 \mathrm{E}-17$ & $9.75 \mathrm{E}-01$ & $9.98 \mathrm{E}-02$ & $1.70 \mathrm{E}-18$ & $3.38 \mathrm{E}-01$ & $4.39 \mathrm{E}-20$ & $\mathbf{5 . 2 2 E}-\mathbf{2 6}$ \\
$\mathrm{F}_{7}$ & Ave & $6.79 \mathrm{E}-04$ & $6.92 \mathrm{E}-02$ & $7.68 \mathrm{E}-01$ & $3.88 \mathrm{E}-02$ & $2.02 \mathrm{E}-02$ & $5.37 \mathrm{E}-01$ & $7.80 \mathrm{E}-04$ & $2.71 \mathrm{E}-05$ & $\mathbf{3 . 3 3 E}-\mathbf{0 8}$ \\
& std & $3.29 \mathrm{E}-03$ & $2.87 \mathrm{E}-02$ & $2.77 \mathrm{E}+00$ & $5.79 \mathrm{E}-02$ & $7.43 \mathrm{E}-03$ & $1.89 \mathrm{E}-01$ & $3.85 \mathrm{E}-04$ & $9.26 \mathrm{E}-06$ & $\mathbf{1 . 1 8 E}-\mathbf{0 6}$ \\
\hline
\end{tabular}

The scientific notation is applied to expressse the results, in which E means multiplied by the power of 10

The bold data indicate which algorithm provided the most appropriate solution for the objective function than the other algorithms

Table 2 Results for MSA and other algorithms on Multimodal test functions

\begin{tabular}{lllllllllll}
\hline & & GA & PSO & GSA & TLBO & GOA & GWO & SHO & EPO \\
\hline $\mathrm{F}_{8}$ & Ave & $-5.11 \mathrm{E}+02$ & $-5.01 \mathrm{E}+02$ & $-2.75 \mathrm{E}+02$ & $-3.81 \mathrm{E}+02$ & $-6.92 \mathrm{E}+02$ & $-4.69 \mathrm{E}+01$ & $-6.14 \mathrm{E}+02$ & $-8.76 \mathrm{E}+02$ & $\mathbf{- 1 . 2 E}+\mathbf{0 4}$ \\
& std & $4.37 \mathrm{E}+01$ & $4.28 \mathrm{E}+01$ & $5.72 \mathrm{E}+01$ & $2.83 \mathrm{E}+01$ & $9.19 \mathrm{E}+01$ & $3.94 \mathrm{E}+01$ & $9.32 \mathrm{E}+01$ & $5.92 \mathrm{E}+01$ & $\mathbf{9 . 1 4 E}-\mathbf{1 2}$ \\
$\mathrm{F}_{9}$ & Ave & $1.23 \mathrm{E}-01$ & $1.20 \mathrm{E}-01$ & $3.35 \mathrm{E}+01$ & $2.23 \mathrm{E}+01$ & $1.01 \mathrm{E}+02$ & $4.85 \mathrm{E}-02$ & $4.34 \mathrm{E}-01$ & $\mathbf{8 . 7 6 E}-\mathbf{0 4}$ & $6.90 \mathrm{E}-03$ \\
& std & $4.11 \mathrm{E}+01$ & $4.01 \mathrm{E}+01$ & $1.19 \mathrm{E}+01$ & $3.25 \mathrm{E}+01$ & $1.89 \mathrm{E}+01$ & $3.91 \mathrm{E}+01$ & $1.66 \mathrm{E}+00$ & $\mathbf{4 . 8 5 E}-\mathbf{0 2}$ & $4.81 \mathrm{E}-02$ \\
$\mathrm{~F}_{10}$ & Ave & $5.31 \mathrm{E}-11$ & $5.20 \mathrm{E}-11$ & $8.25 \mathrm{E}-09$ & $1.55 \mathrm{E}+01$ & $1.15 \mathrm{E}+00$ & $2.83 \mathrm{E}-08$ & $1.63 \mathrm{E}-14$ & $8.03 \mathrm{E}-16$ & $\mathbf{8 . 0 4 E}-\mathbf{2 0}$ \\
& std & $1.11 \mathrm{E}-10$ & $1.08 \mathrm{E}-10$ & $1.90 \mathrm{E}-09$ & $8.11 \mathrm{E}+00$ & $7.87 \mathrm{E}-01$ & $4.34 \mathrm{E}-07$ & $3.14 \mathrm{E}-15$ & $2.74 \mathrm{E}-14$ & $\mathbf{3 . 3 4 E}-\mathbf{1 8}$ \\
$\mathrm{F}_{11}$ & Ave & $3.31 \mathrm{E}-06$ & $3.24 \mathrm{E}-06$ & $8.19 \mathrm{E}+00$ & $3.01 \mathrm{E}-01$ & $5.74 \mathrm{E}-01$ & $2.49 \mathrm{E}-05$ & $2.29 \mathrm{E}-03$ & $\mathbf{4 . 2 0 E}-\mathbf{1 1}$ & $4.23 \mathrm{E}-10$ \\
& std & $4.23 \mathrm{E}-05$ & $4.11 \mathrm{E}-05$ & $3.70 \mathrm{E}+00$ & $2.89 \mathrm{E}-01$ & $1.12 \mathrm{E}-01$ & $1.34 \mathrm{E}-04$ & $5.24 \mathrm{E}-03$ & $\mathbf{4 . 7 3 E}-\mathbf{0 8}$ & $5.11 \mathrm{E}-07$ \\
$\mathrm{~F}_{12}$ & Ave & $9.16 \mathrm{E}-08$ & $8.93 \mathrm{E}-08$ & $2.65 \mathrm{E}-01$ & $5.21 \mathrm{E}+01$ & $1.27 \mathrm{E}+00$ & $1.34 \mathrm{E}-05$ & $3.93 \mathrm{E}-02$ & $5.09 \mathrm{E}-03$ & $\mathbf{6 . 3 3 E}-\mathbf{0 5}$ \\
& std & $4.88 \mathrm{E}-07$ & $4.77 \mathrm{E}-07$ & $3.14 \mathrm{E}-01$ & $2.47 \mathrm{E}+02$ & $1.02 \mathrm{E}+00$ & $6.23 \mathrm{E}-04$ & $2.42 \mathrm{E}-02$ & $3.75 \mathrm{E}-03$ & $\mathbf{4 . 7 1 E}-\mathbf{0 4}$ \\
$\mathrm{F}_{13}$ & Ave & $6.39 \mathrm{E}-02$ & $6.26 \mathrm{E}-02$ & $5.73 \mathrm{E}-32$ & $2.81 \mathrm{E}+02$ & $6.60 \mathrm{E}-02$ & $9.94 \mathrm{E}-08$ & $4.75 \mathrm{E}-01$ & $1.25 \mathrm{E}-08$ & $\mathbf{0 . 0 0 E}+\mathbf{0 0}$ \\
& std & $4.49 \mathrm{E}-02$ & $4.39 \mathrm{E}-02$ & $8.95 \mathrm{E}-32$ & $8.63 \mathrm{E}+02$ & $4.33 \mathrm{E}-02$ & $2.61 \mathrm{E}-07$ & $2.38 \mathrm{E}-01$ & $2.61 \mathrm{E}-07$ & $\mathbf{0 . 0 0 E}+\mathbf{0 0}$ \\
\hline
\end{tabular}

The scientific notation is applied to expressse the results, in which $\mathrm{E}$ means multiplied by the power of 10

The bold data indicate which algorithm provided the most appropriate solution for the objective function than the other algorithms

that MSA obtains very competitive results in majority of the benchmark test problems.

\subsubsection{Statistical testing}

In addition to standard statistical analysis (i.e. mean and standard deviation), the analysis of variance (ANOVA) test is carried out. ANOVA test is used to determine whether 
Table 3 Results for MSA and other algorithms on multimodal test functions with low dimension

\begin{tabular}{|c|c|c|c|c|c|c|c|c|c|c|}
\hline & & GA & PSO & GSA & TLBO & GOA & GWO & $\mathrm{SHO}$ & EPO & MSA \\
\hline \multirow[t]{2}{*}{$\mathrm{F}_{14}$} & /e & $9 \mathrm{E}+00$ & $2.77 \mathrm{E}+00$ & $61 \mathrm{E}+00$ & $6.79 \mathrm{E}+00$ & $9.98 \mathrm{E}+01$ & $1.26 \mathrm{E}+00$ & $3.71 \mathrm{E}+00$ & $1.08 \mathrm{E}+00$ & -01 \\
\hline & stc & 4. & 0 & 0 & 0 & -1 & 01 & 00 & 02 & 12 \\
\hline \multirow[t]{2}{*}{$\mathrm{F}_{15}$} & Ave & 7 & 3 & 02 & 2 & 02 & 2 & 02 & 03 & $3.3 E-04$ \\
\hline & std & 2. & 03 & 02 & 03 & 1.26 & 03 & 02 & -03 & -05 \\
\hline \multirow[t]{2}{*}{$\mathrm{F}_{16}$} & Ave & $-1.02 \mathrm{E}+00$ & $-1.02 \mathrm{E}+00$ & $-1.02 \mathrm{E}+00$ & +00 & $2 \mathrm{E}+00$ & $E+00$ & $E+00$ & $-1.03 E+00$ & $E+00$ \\
\hline & std & -07 & 0.00 & $0.00 \mathrm{E}+00$ & 3.64 & $4.74 \mathrm{E}-08$ & $3.23 \mathrm{E}-05$ & $7.02 \mathrm{E}$ & -11 & -10 \\
\hline \multirow[t]{2}{*}{$F_{17}$} & Ave & 01 & 01 & -01 & $3.98 \mathrm{E}-01$ & $3.98 \mathrm{E}-01$ & $3.98 \mathrm{E}-01$ & $3.98 \mathrm{E}-01$ & $3.98 \mathrm{E}-01$ & $3.98 \mathrm{E}-01$ \\
\hline & std & 3.7 & 9.03 & 6 & 9.4 & 07 & 7.6 & 7.00 & 05 & -21 \\
\hline \multirow[t]{2}{*}{$\mathrm{F}_{18}$} & Ave & 3 & $E+00$ & 3.00 & +00 & $0 \mathrm{E}+00$ & 0 & 0 & & +00 \\
\hline & std & $6.33 \mathrm{E}-07$ & $6.59 \mathrm{E}-05$ & $3.24 \mathrm{E}-02$ & $1.94 \mathrm{E}-10$ & $1.48 \mathrm{E}+01$ & $2.25 \mathrm{E}-05$ & $7.16 \mathrm{E}-06$ & $1.15 \mathrm{E}-08$ & $1.15 E-18$ \\
\hline \multirow[t]{2}{*}{$\mathrm{F}_{19}$} & Ave & $-3.81 \mathrm{E}+00$ & $-3.80 \mathrm{E}+00$ & $-3.86 \mathrm{E}+00$ & $-3.73 E+00$ & $-3.77 \mathrm{E}+00$ & $-3.75 E+00$ & $-3.84 \mathrm{E}+00$ & $-3.86 \mathrm{E}+00$ & $-3.86 E+00$ \\
\hline & std & 4.37E-10 & $3.37 \mathrm{E}-15$ & 4.15E-01 & $9.69 \mathrm{E}-04$ & $3.53 \mathrm{E}-07$ & $2.55 \mathrm{E}-03$ & $1.57 \mathrm{E}-03$ & 6.50 & $5.61 \mathrm{E}-10$ \\
\hline \multirow[t]{2}{*}{$\mathrm{F}_{20}$} & Ave & $-2.39 \mathrm{E}+00$ & $-3.32 E+00$ & $-1.47 \mathrm{E}+00$ & $-2.17 \mathrm{E}+00$ & $-3.23 E+00$ & $-2.84 \mathrm{E}+00$ & $-3.27 \mathrm{E}+00$ & $-2.81 \mathrm{E}+00$ & $-3.31 \mathrm{E}+00$ \\
\hline & std & 4.37E-01 & $2.66 \mathrm{E}-01$ & $5.32 \mathrm{E}-01$ & $1.64 \mathrm{E}-01$ & $5.37 \mathrm{E}-02$ & $3.71 \mathrm{E}-01$ & 7.27E-02 & $7.11 \mathrm{E}-01$ & 4.29E-05 \\
\hline \multirow[t]{2}{*}{$F_{21}$} & Ave & $-5.19 \mathrm{E}+00$ & $-7.54 \mathrm{E}+00$ & $-4.57 \mathrm{E}+00$ & $-7.33 \mathrm{E}+00$ & $-7.38 \mathrm{E}+00$ & $-2.28 \mathrm{E}+00$ & $-9.65 E+00$ & $-8.07 \mathrm{E}+00$ & $-10.15 E+00$ \\
\hline & std & $2.34 \mathrm{E}+00$ & $2.77 \mathrm{E}+00$ & $1.30 \mathrm{E}+00$ & $1.29 \mathrm{E}+00$ & $2.91 \mathrm{E}+00$ & $1.80 \mathrm{E}+00$ & $1.54 \mathrm{E}+00$ & $2.29 \mathrm{E}+00$ & $1.25 \mathrm{E}-02$ \\
\hline \multirow[t]{2}{*}{$\mathrm{F}_{22}$} & Ave & $-2.97 \mathrm{E}+00$ & $-8.55 \mathrm{E}+00$ & $-6.58 \mathrm{E}+00$ & $-1.00 \mathrm{E}+00$ & $-8.50 \mathrm{E}+00$ & $-3.99 \mathrm{E}+00$ & $-1.04 \mathrm{E}+00$ & $-10.01 E+00$ & $-10.40 \mathrm{E}+00$ \\
\hline & std & $1.37 \mathrm{E}-02$ & $3.08 \mathrm{E}+00$ & $2.64 \mathrm{E}+00$ & $2.89 \mathrm{E}-04$ & $3.02 \mathrm{E}+00$ & $1.99 \mathrm{E}+00$ & $2.73 \mathrm{E}-04$ & $3.97 \mathrm{E}-02$ & $3.65 \mathrm{E}-07$ \\
\hline \multirow[t]{2}{*}{$\mathrm{F}_{23}$} & Ave & $-3.10 \mathrm{E}+00$ & $-9.19 \mathrm{E}+00$ & $-9.37 E+00$ & $-2.46 \mathrm{E}+00$ & $-8.41 \mathrm{E}+00$ & $-4.49 \mathrm{E}+00$ & $-1.05 E+01$ & $-3.41 \mathrm{E}+00$ & $-10.53 E+00$ \\
\hline & std & $2.37 \mathrm{E}+00$ & $2.52 \mathrm{E}+00$ & $2.75 \mathrm{E}+00$ & $1.19 \mathrm{E}+00$ & $3.13 \mathrm{E}+00$ & $1.96 \mathrm{E}+00$ & $1.81 \mathrm{E}-04$ & $1.11 \mathrm{E}-02$ & $5.26 \mathrm{E}-06$ \\
\hline
\end{tabular}

The scientific notation is applied to expressse the results, in which E means multiplied by the power of 10

The bold data indicate which algorithm provided the most appropriate solution for the objective function than the other algorithms

the results obtained from proposed algorithm are different from other competitor algorithms in a statistically significant way. The sample size for ANOVA test is 30 with $95 \%$ confidence of interval. A $p$-value determine whether the given algorithm is statistically significant or not. If $p$ value of the given algorithm is less than 0.05 , then the corresponding algorithm is statistically significant. Table 4 shows the analysis of ANOVA test on the benchmark test functions. Based on Table 4, the $p$ value obtained from MSA is much smaller than 0.05 for all the benchmark test functions. Therefore, MSA is statistical different from the other mentioned optimization algorithms.

\section{Conclusion}

A novel heuristic optimization algorithm called Momentum Search Algorithm (MSA) is proposed in this paper. It uses the laws of momentum conservation and kinetic energy conservation between bodies in a closed system. The search agents in MSA are a number of bodies with specified mass. Using the momentum law, each body in the system is affected by a separate external body to be conducted towards the optima. To satisfy exploration and exploitation concepts and enhance the performance of the method, the mass and speed of the external body is regulated over the time. The efficiency of MSA is assessed on 23 benchmark test functions. The results show that in 


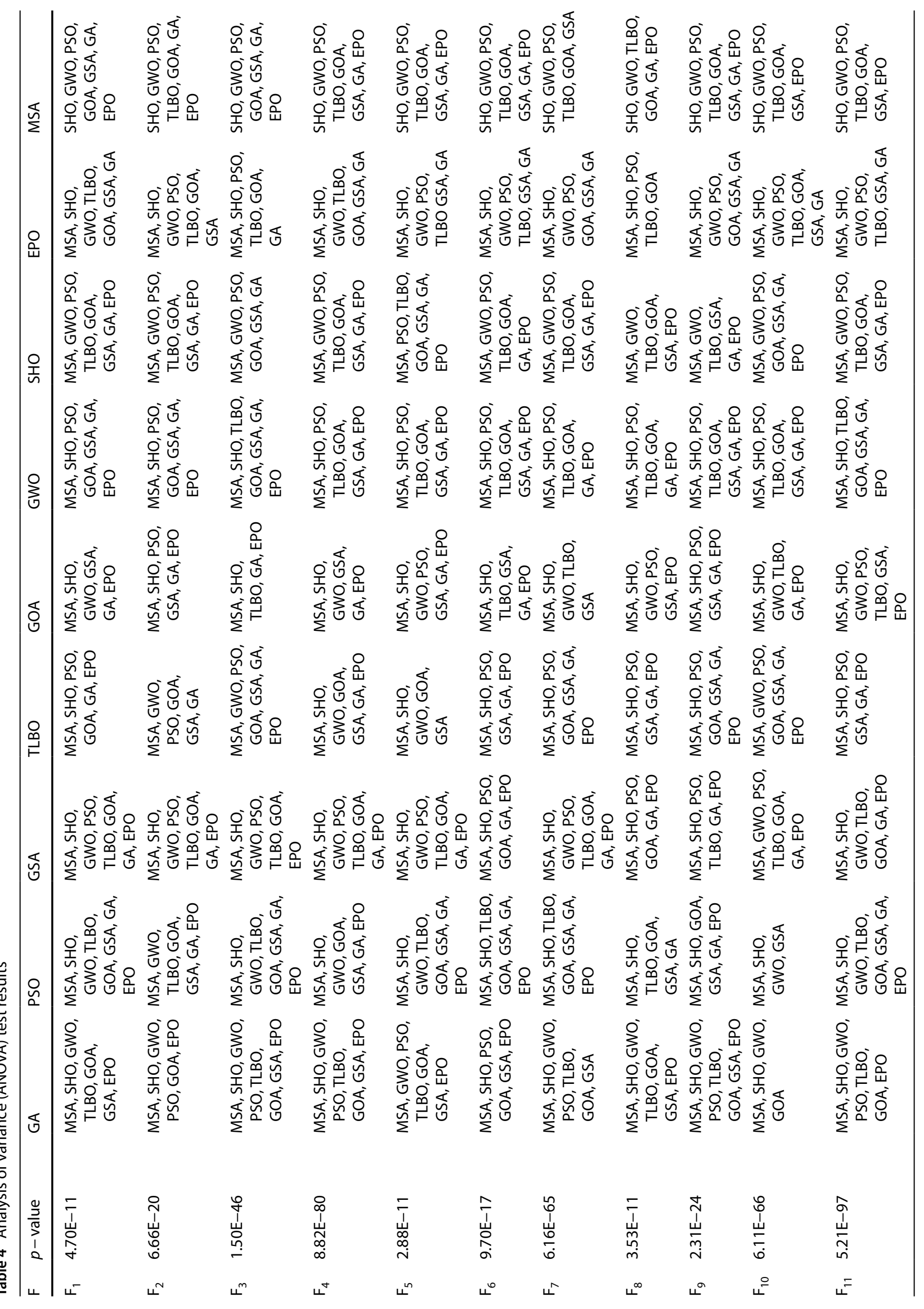




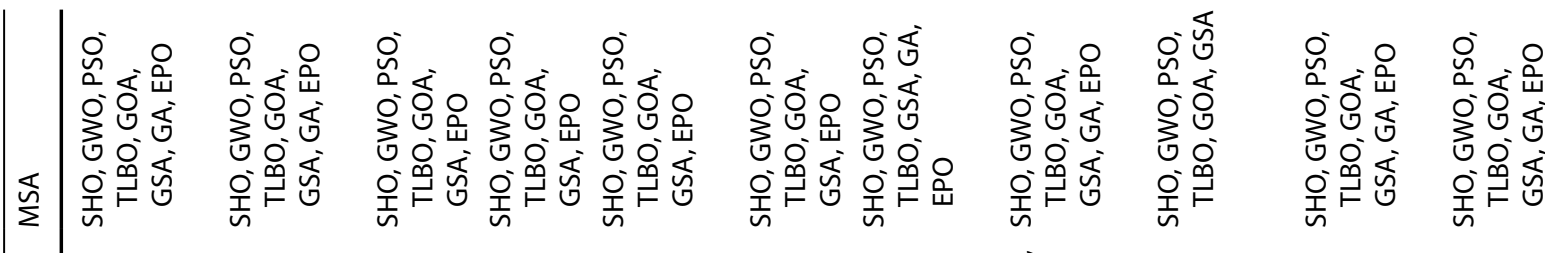

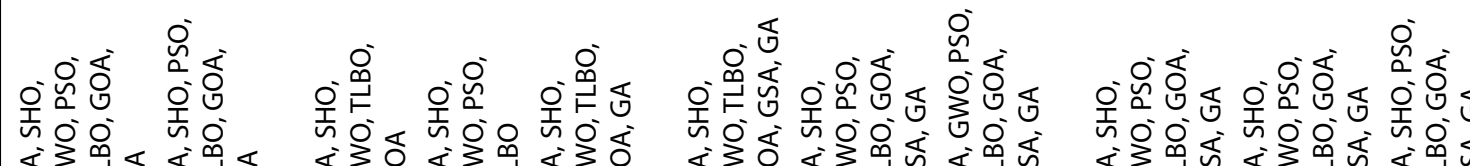
o

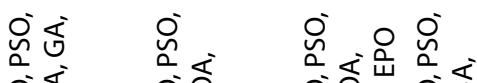

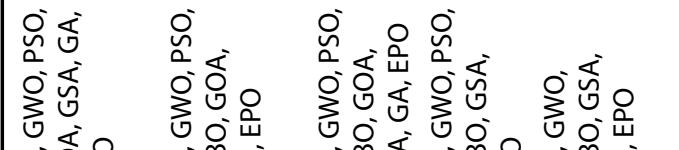

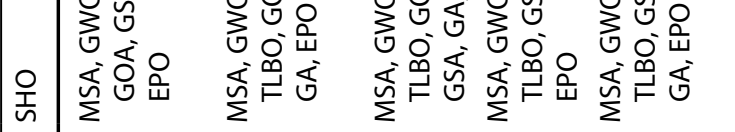

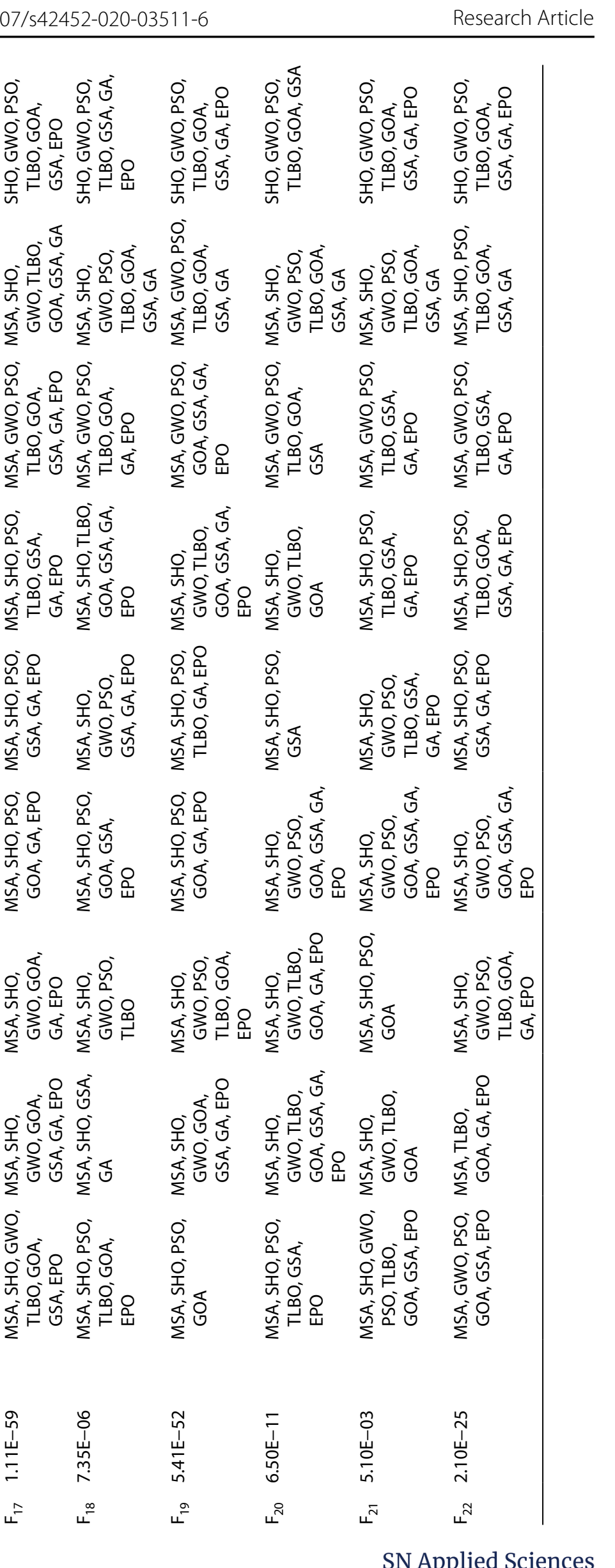

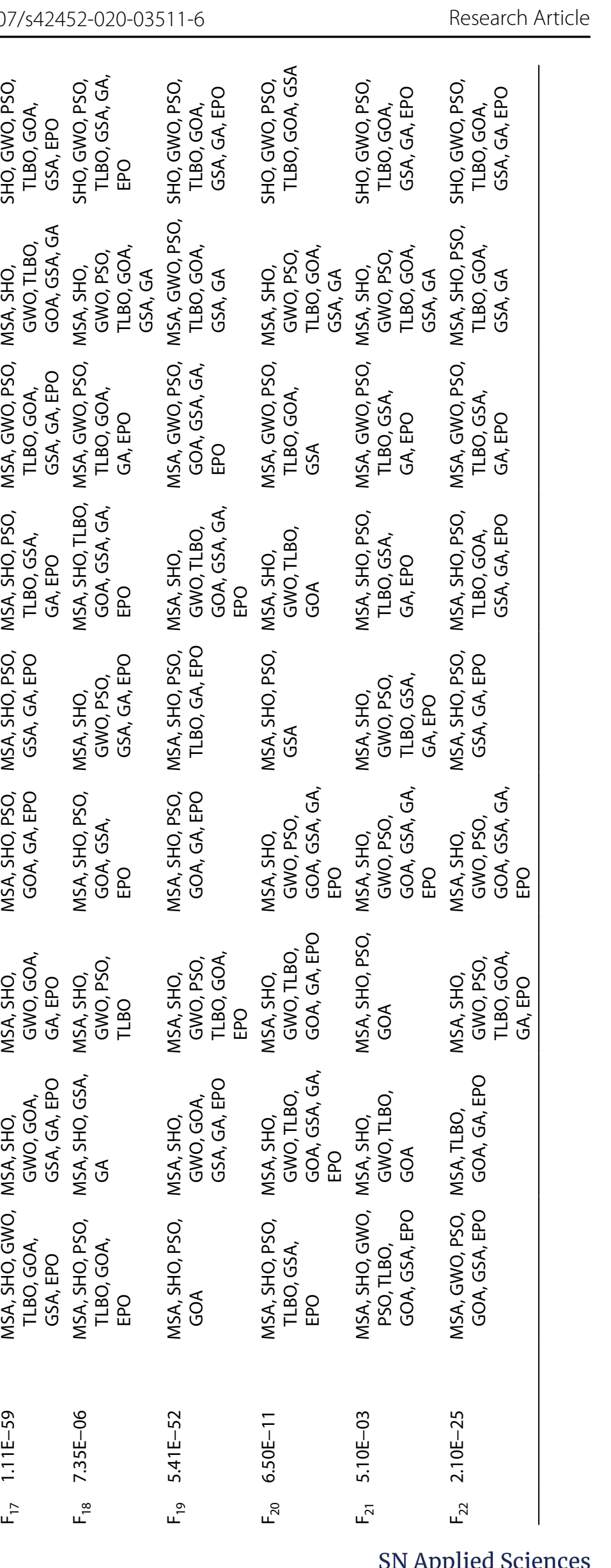

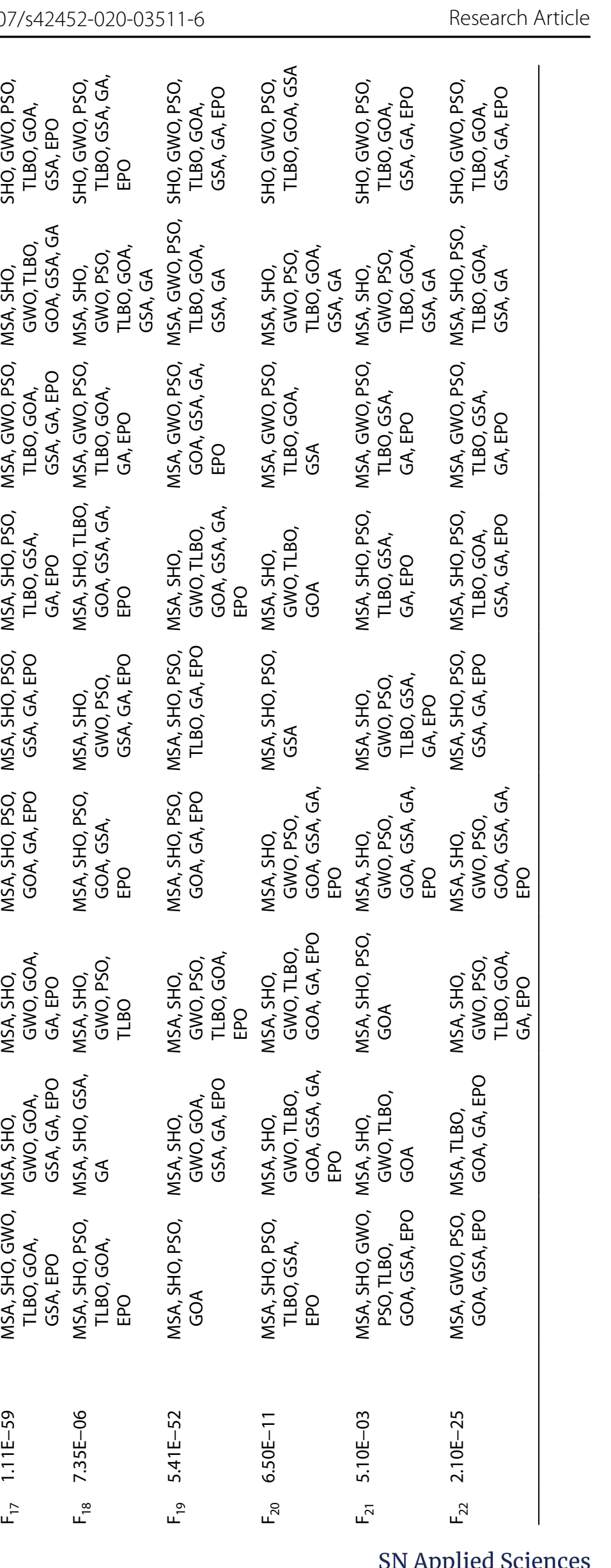

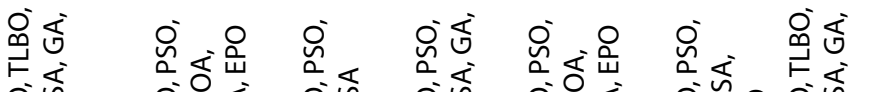

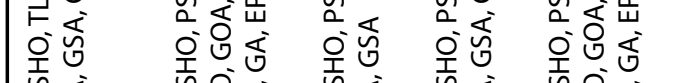

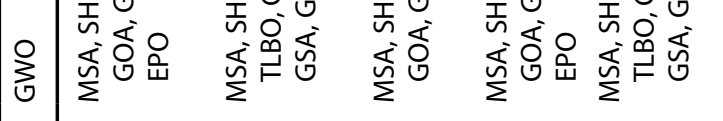

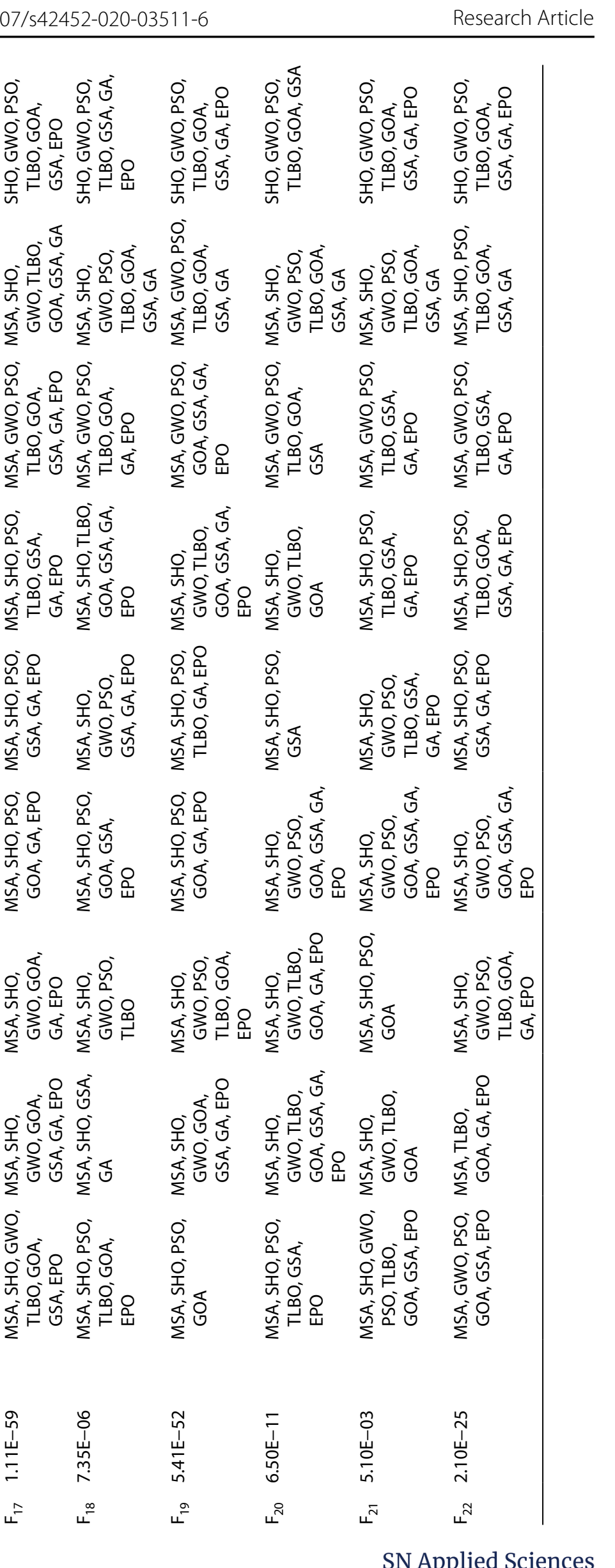

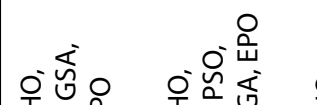

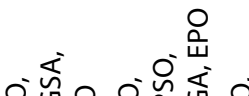

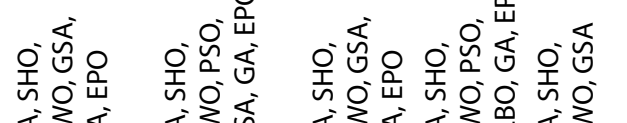

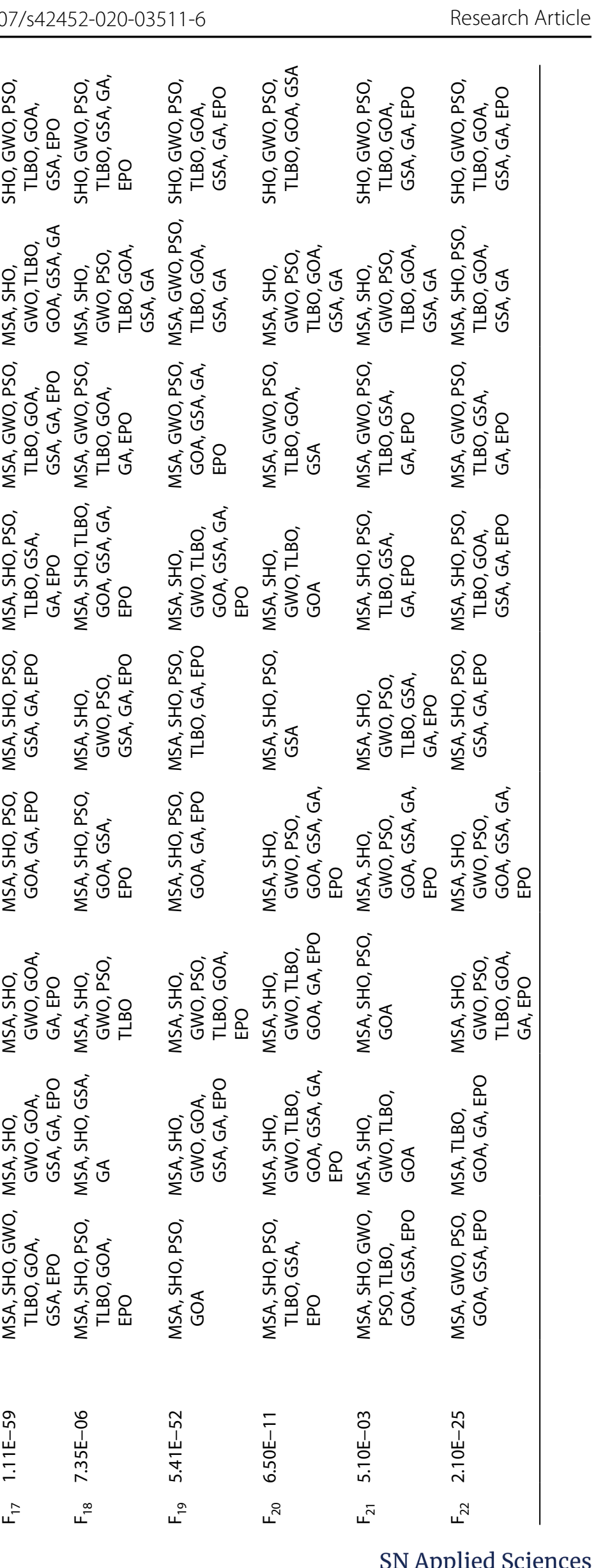

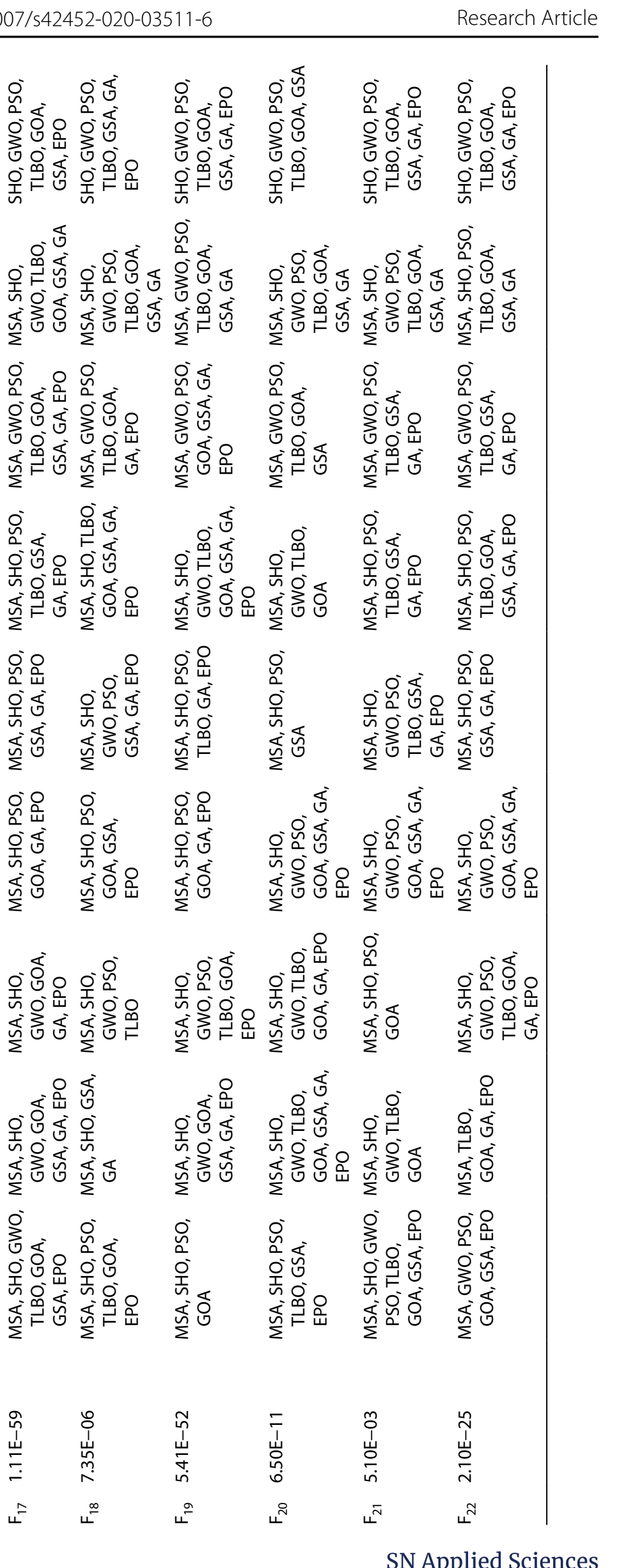

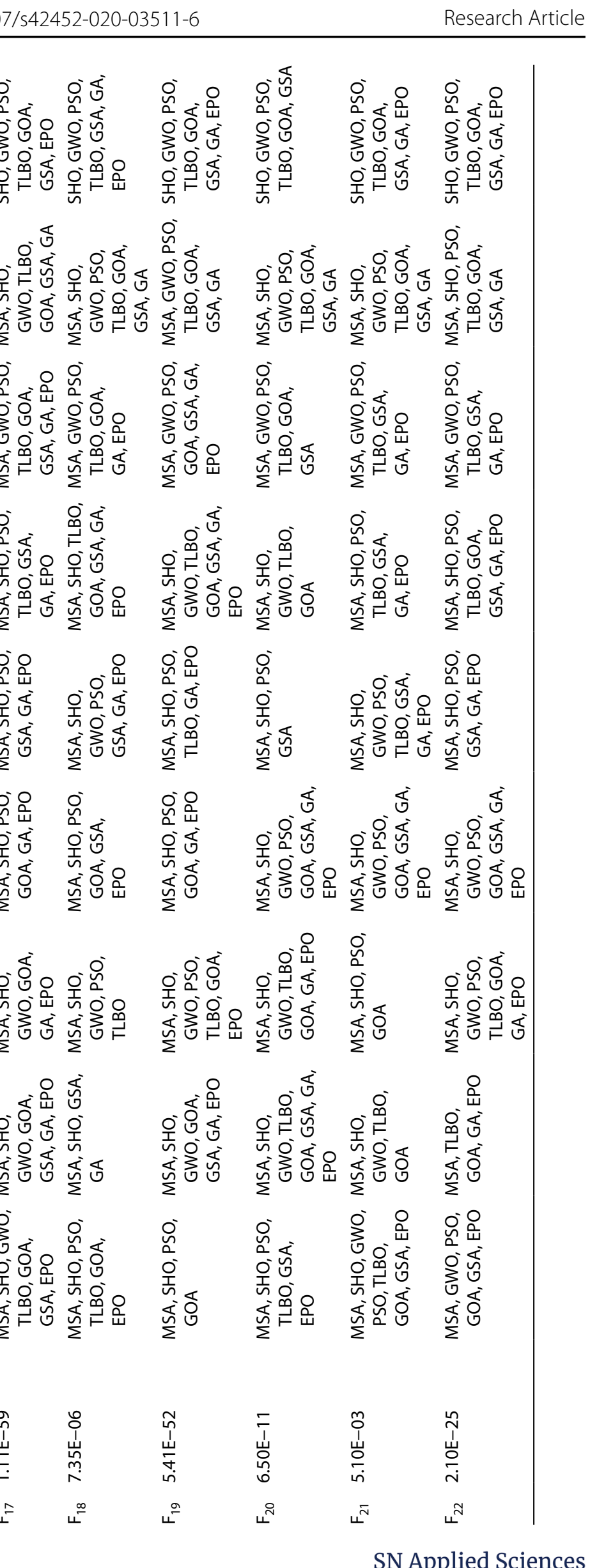

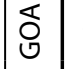

这

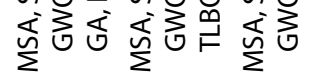

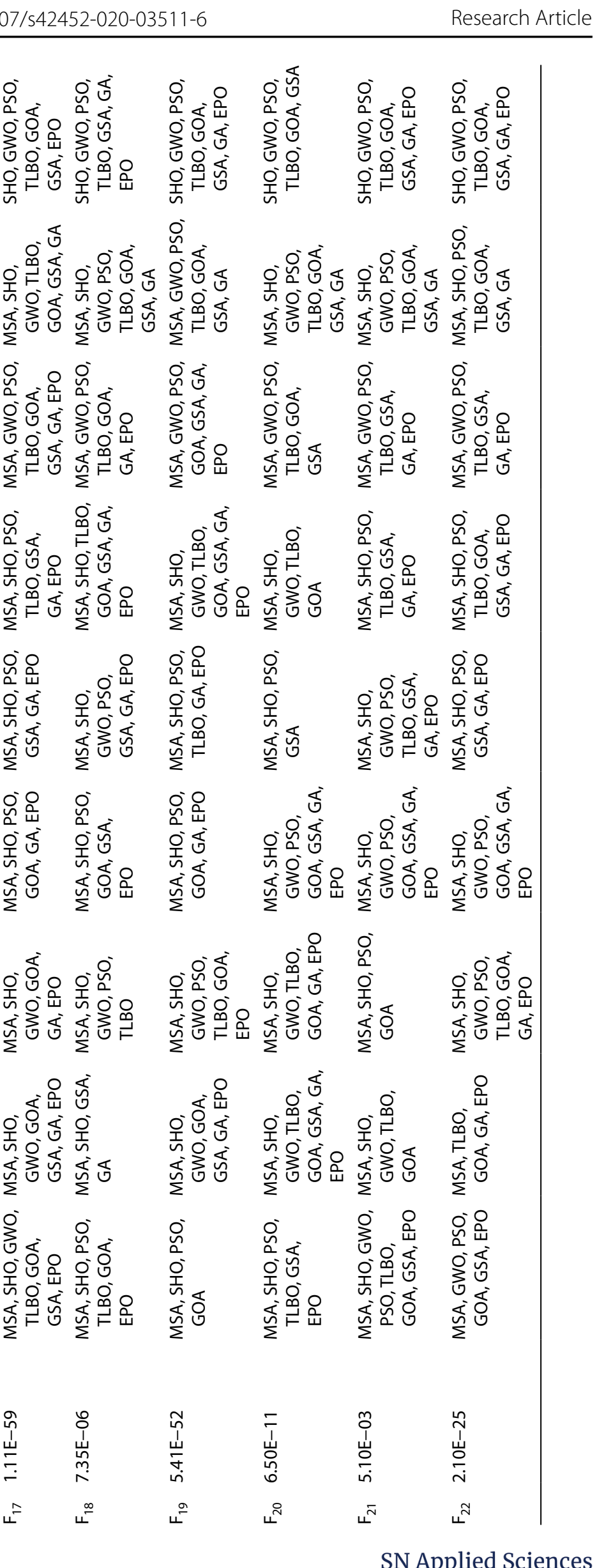

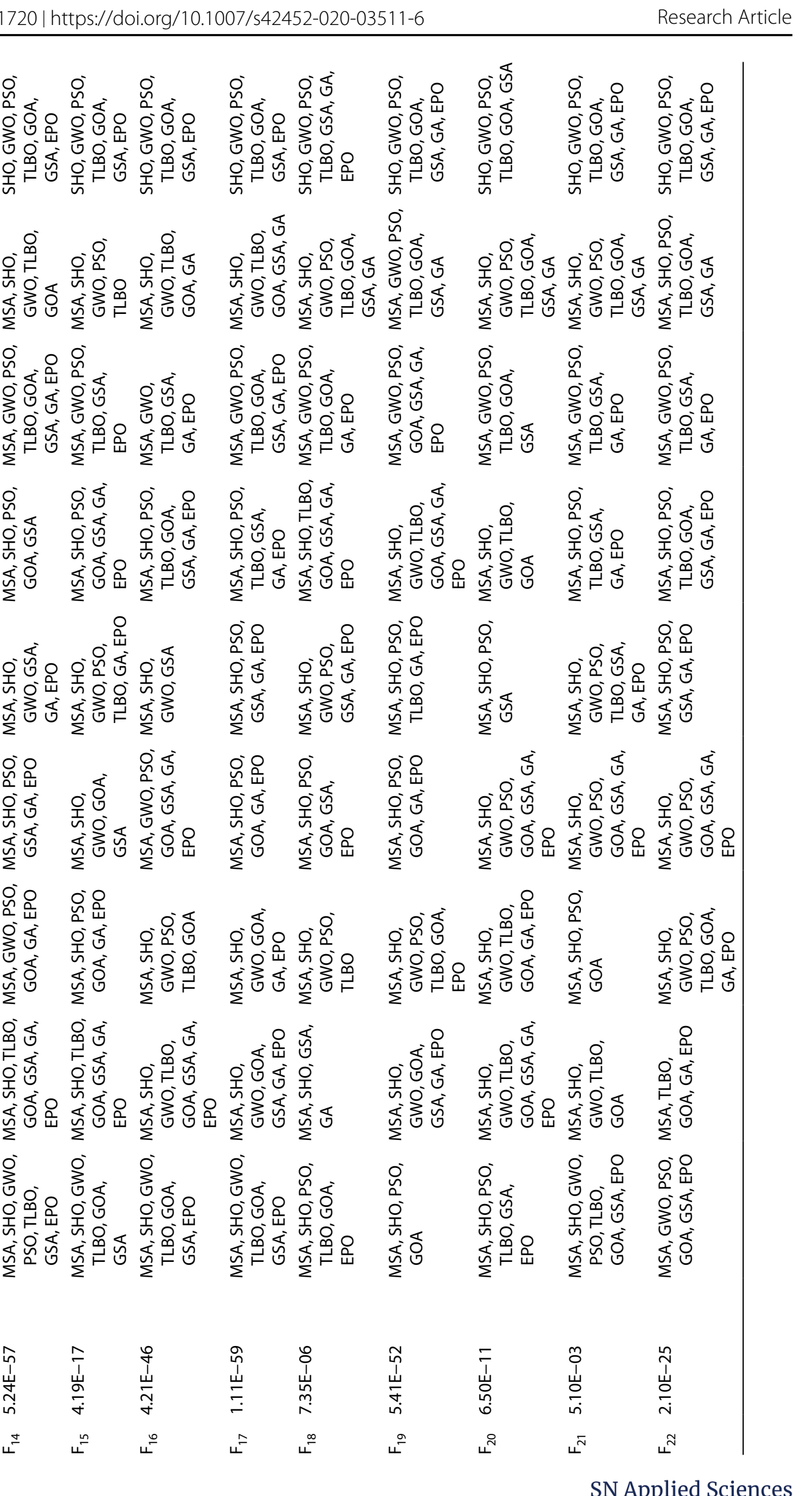

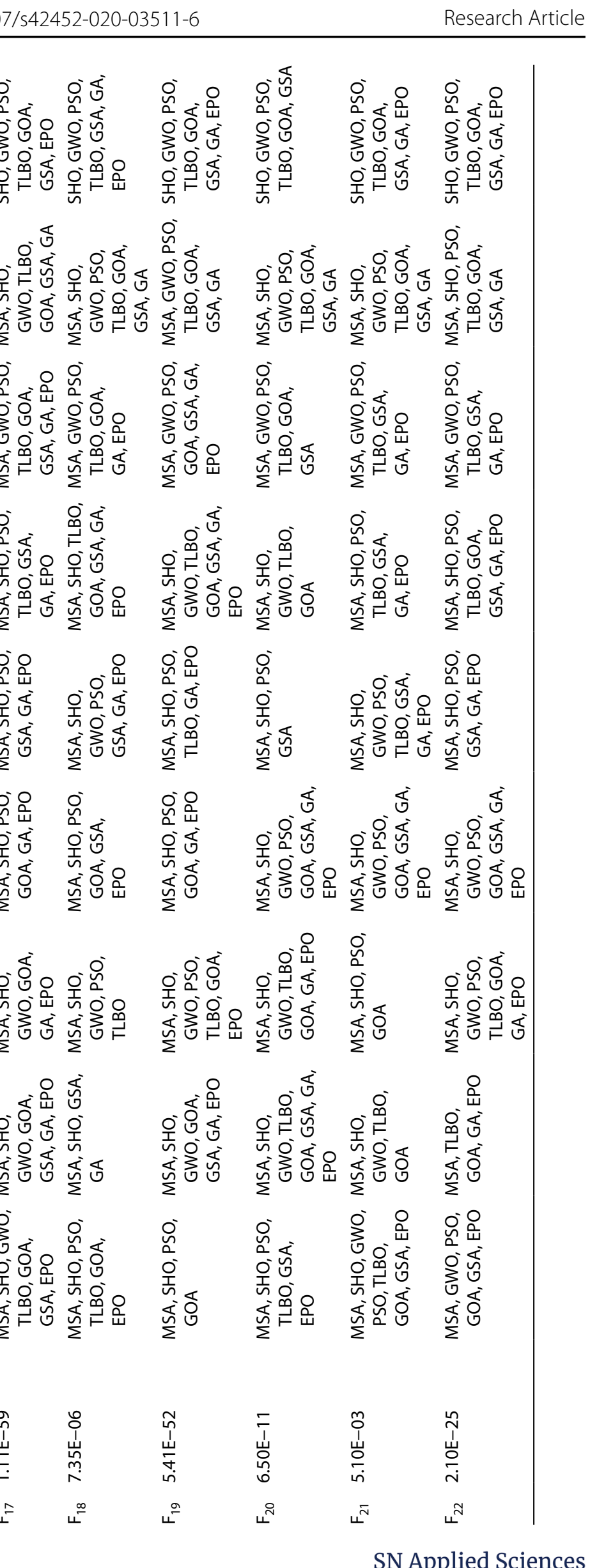

욜

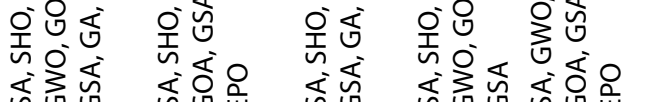

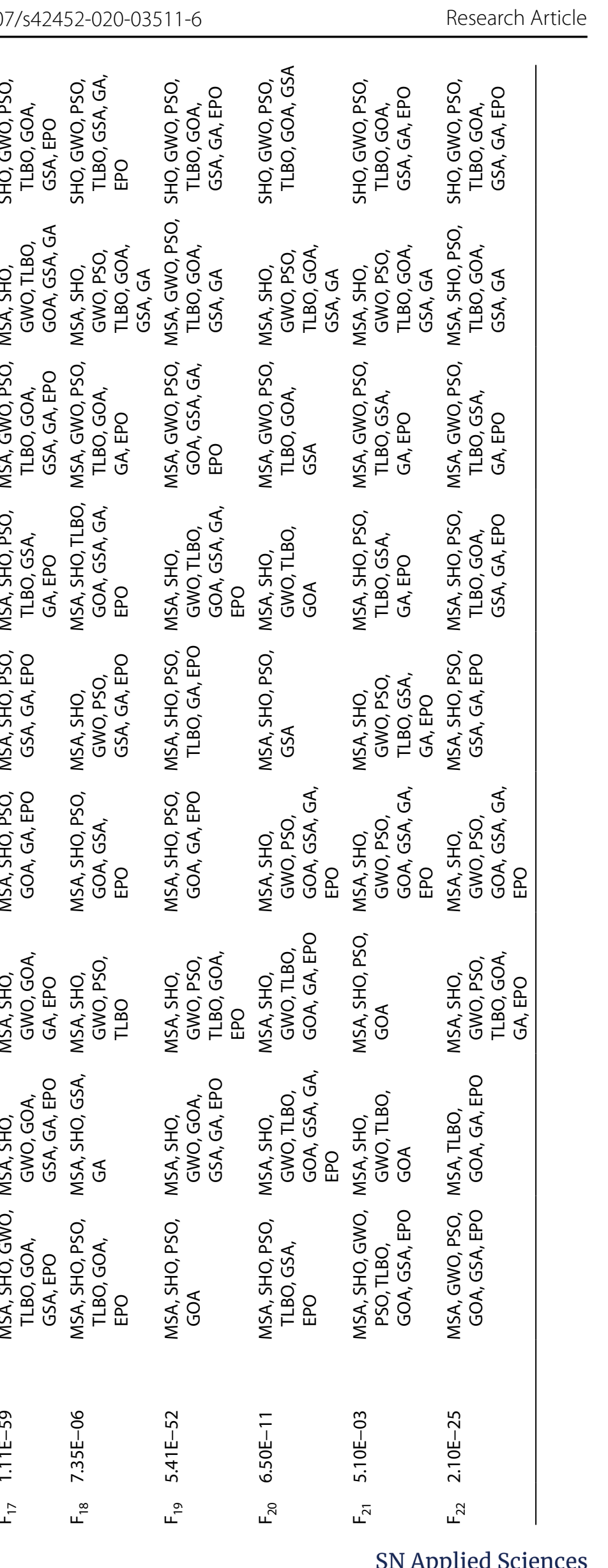

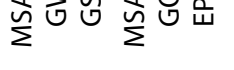

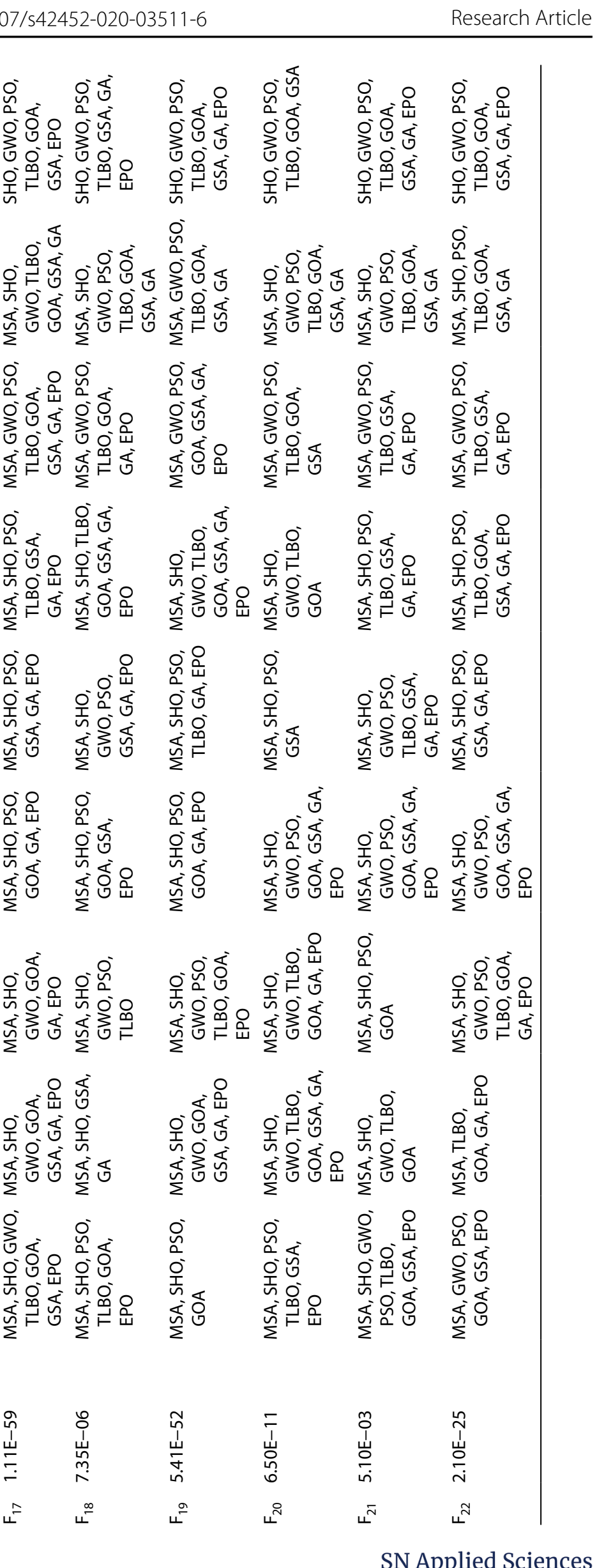

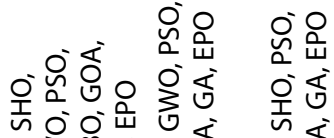

용ำ

온ํํㅇํㅇำ

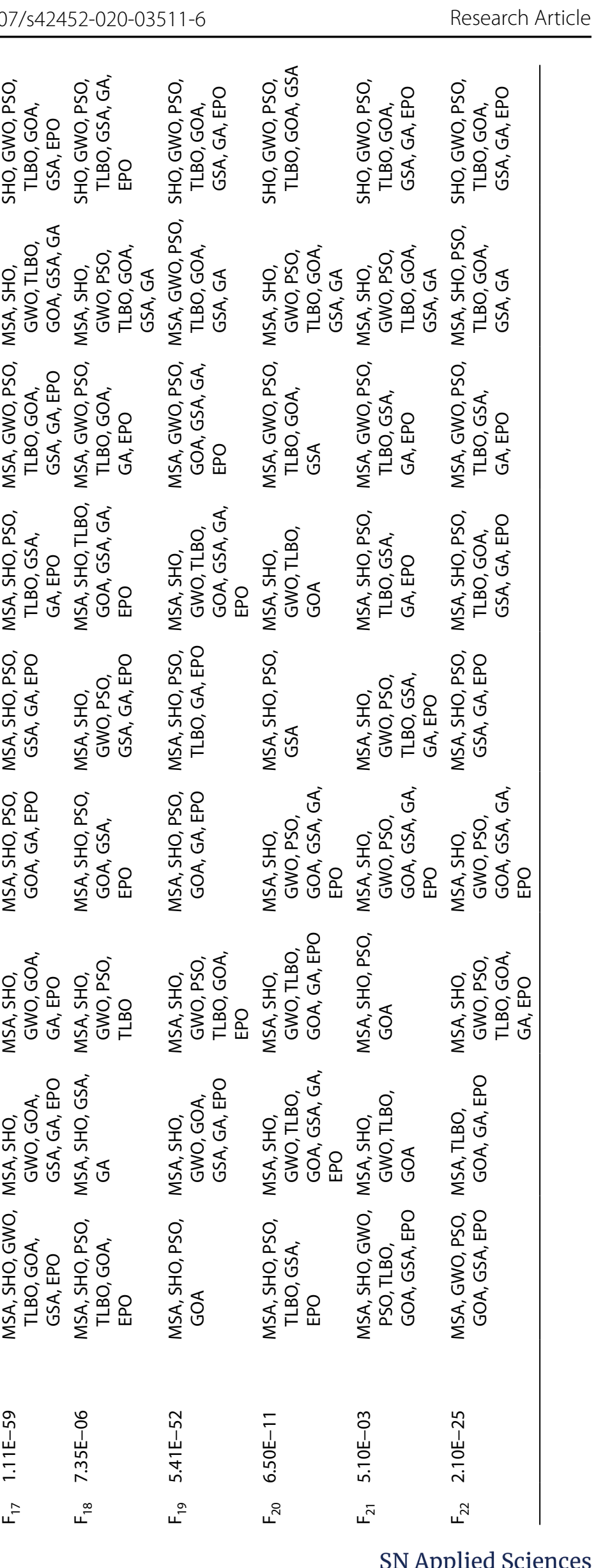

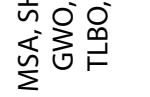

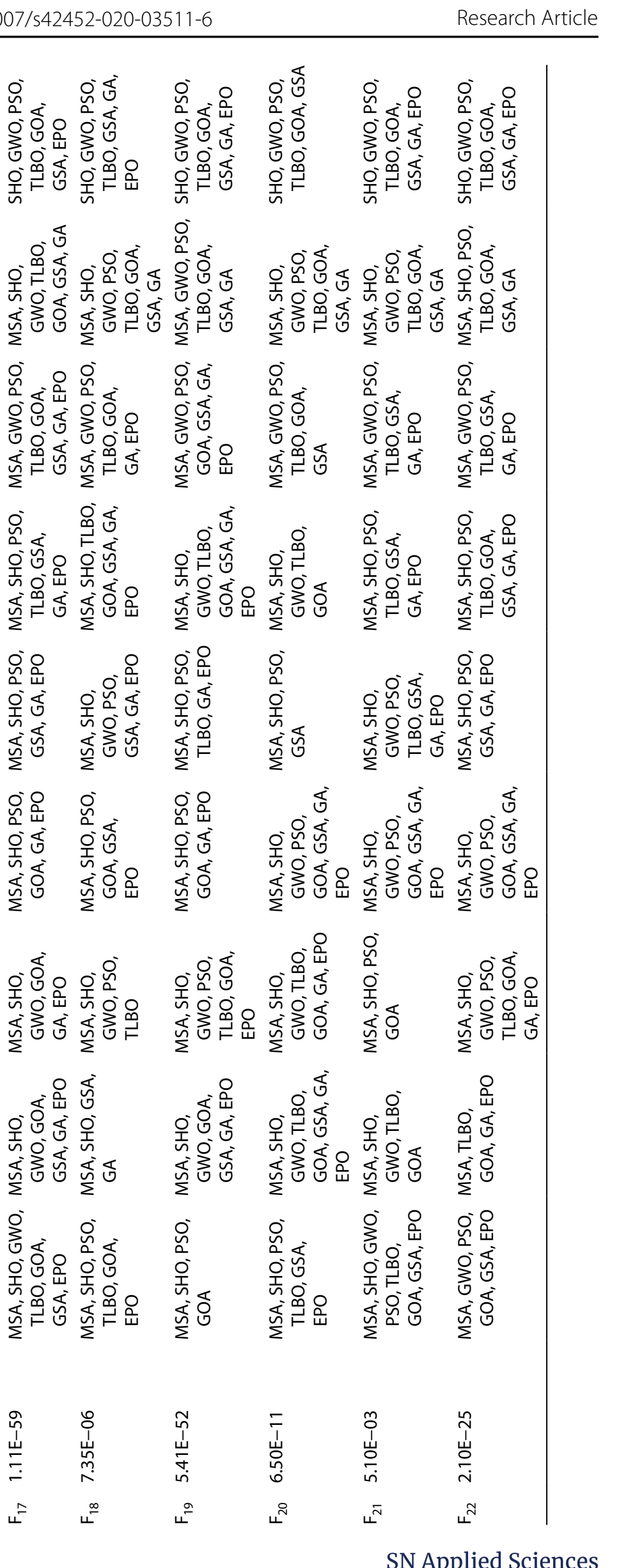

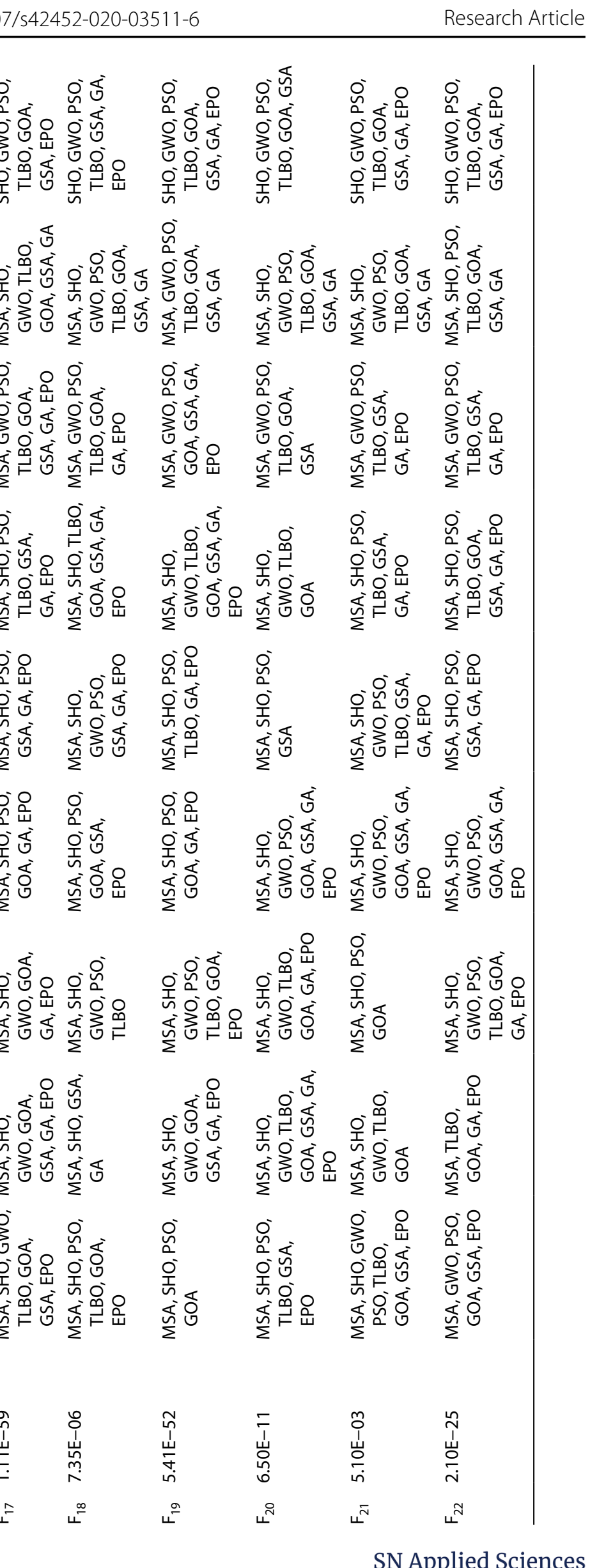

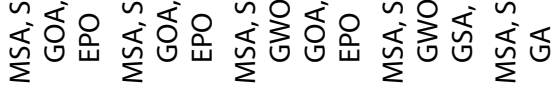

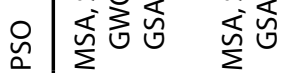

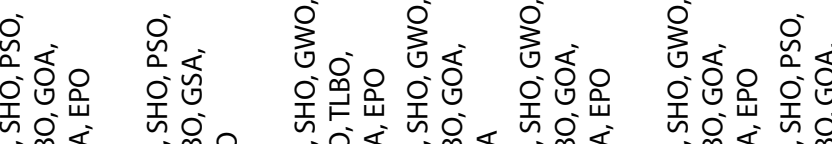

ธิ

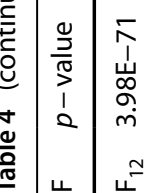

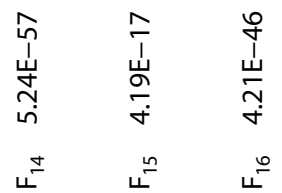

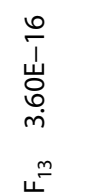

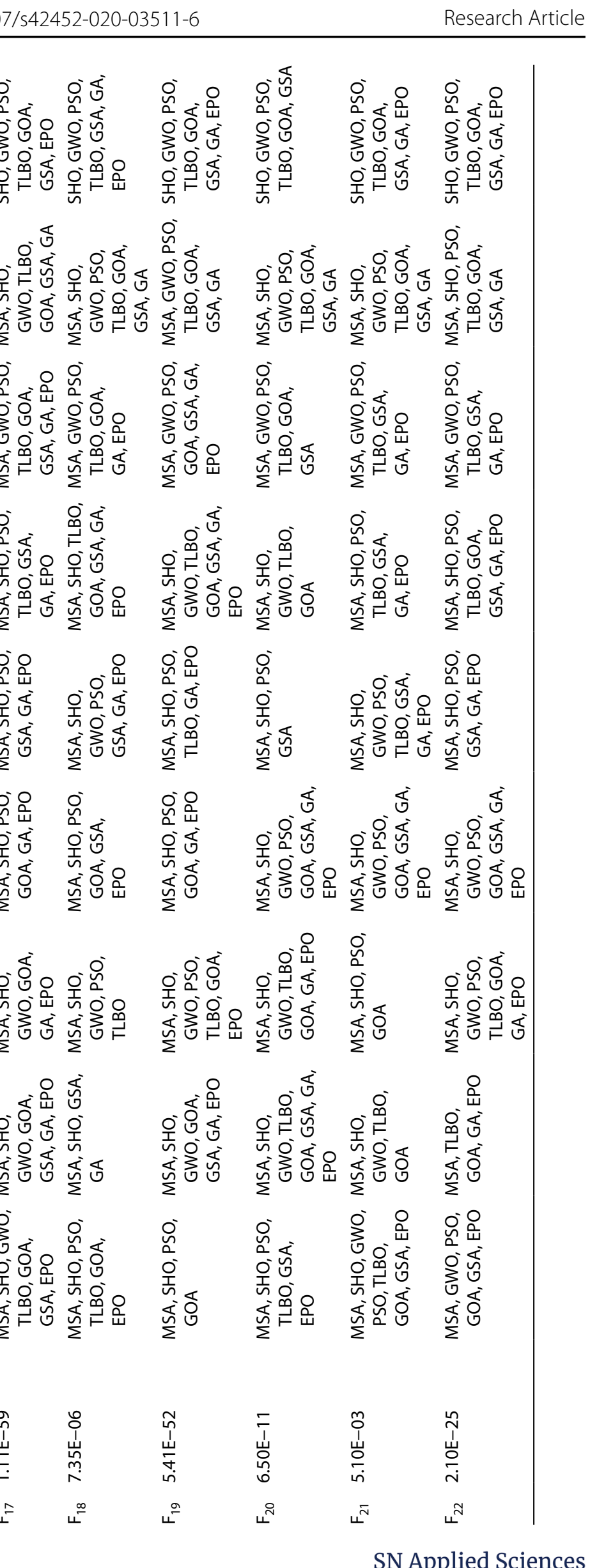

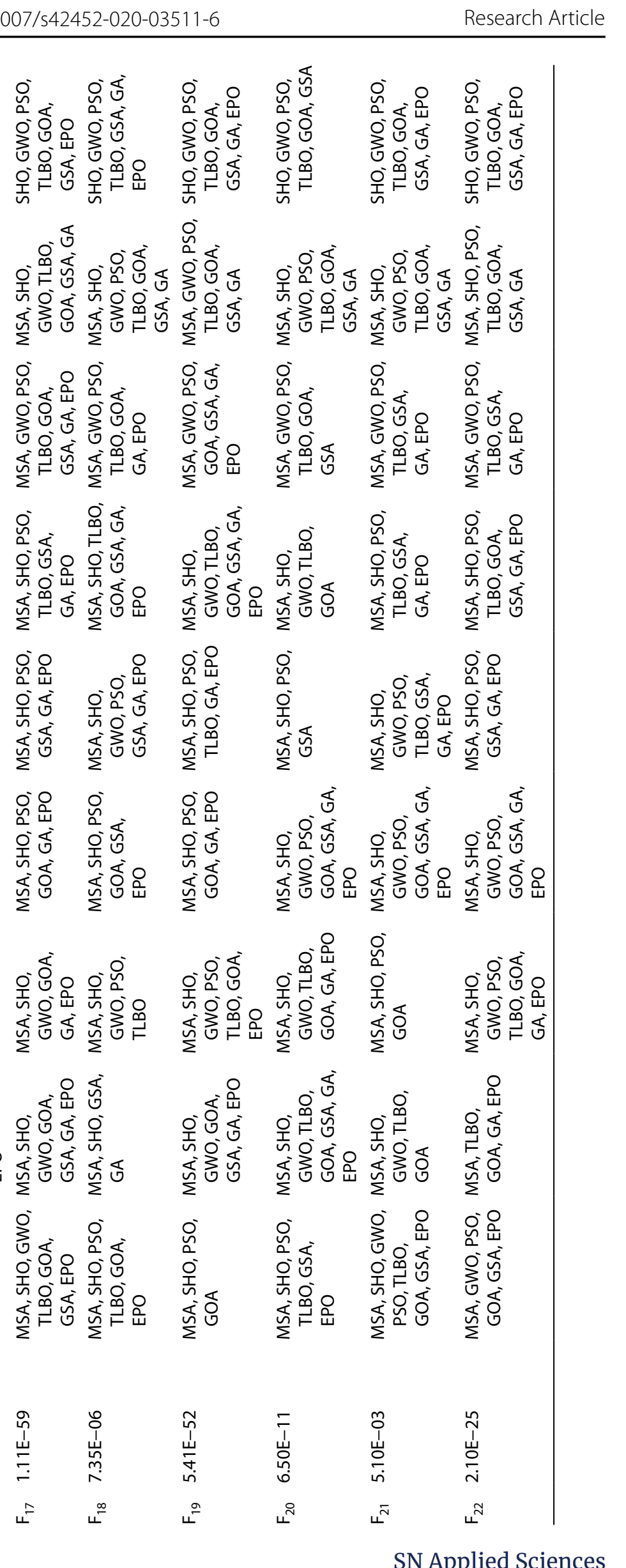

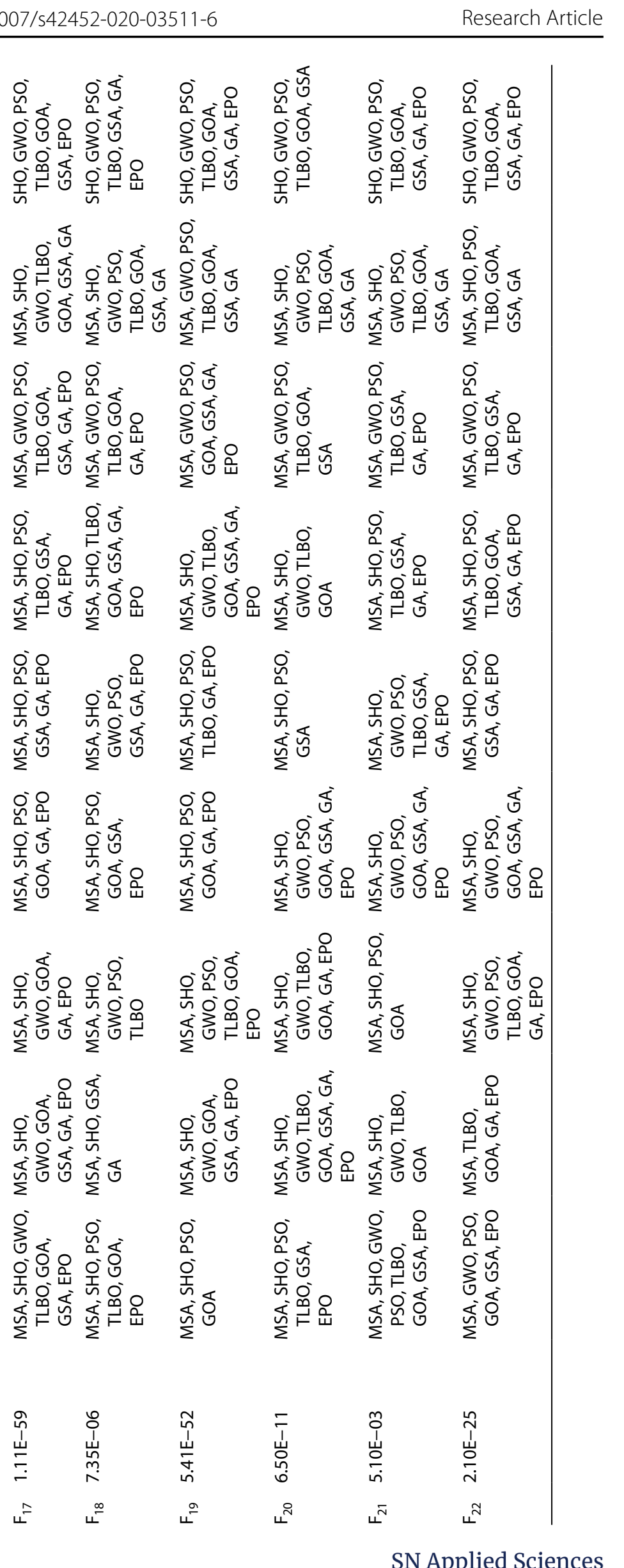

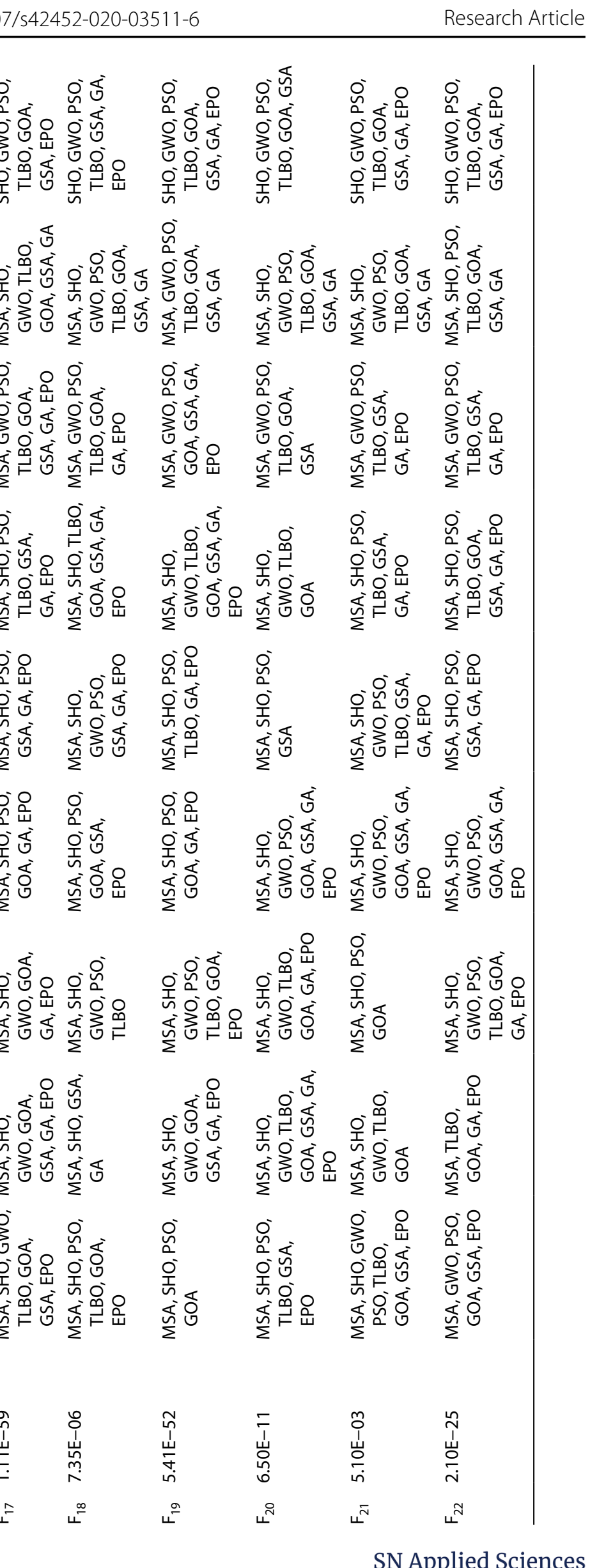

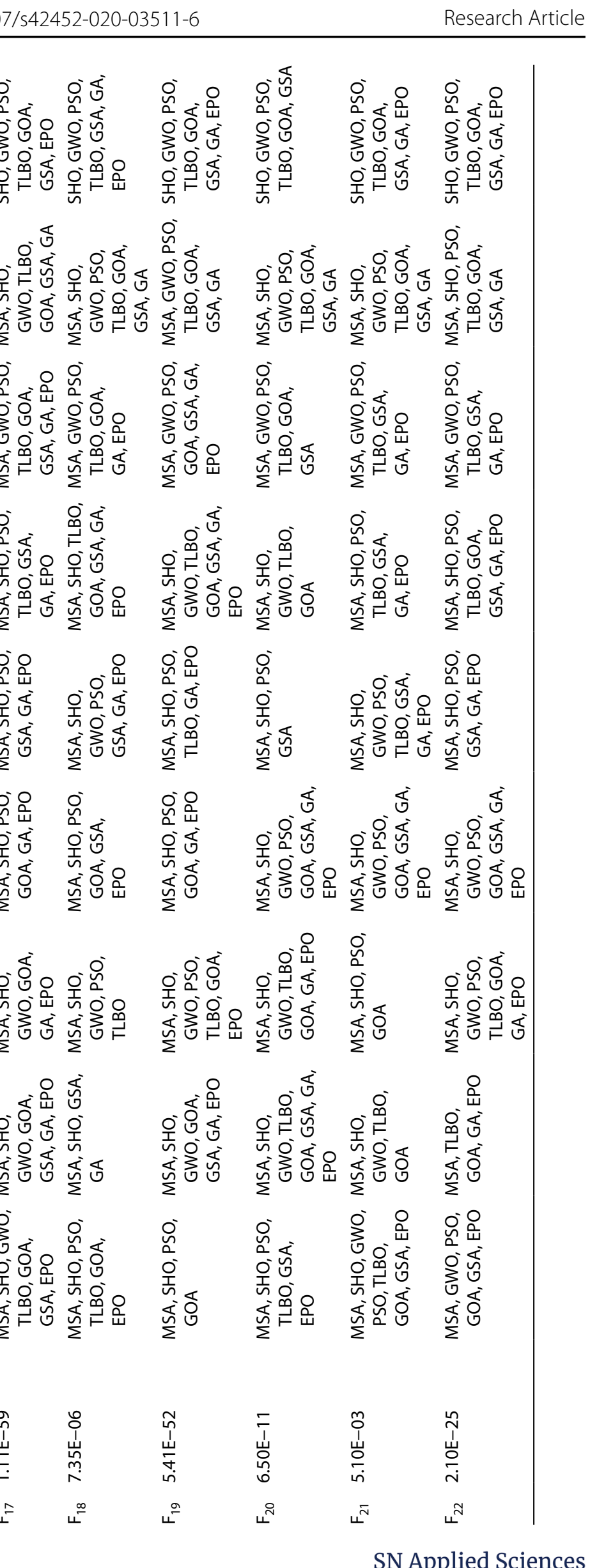

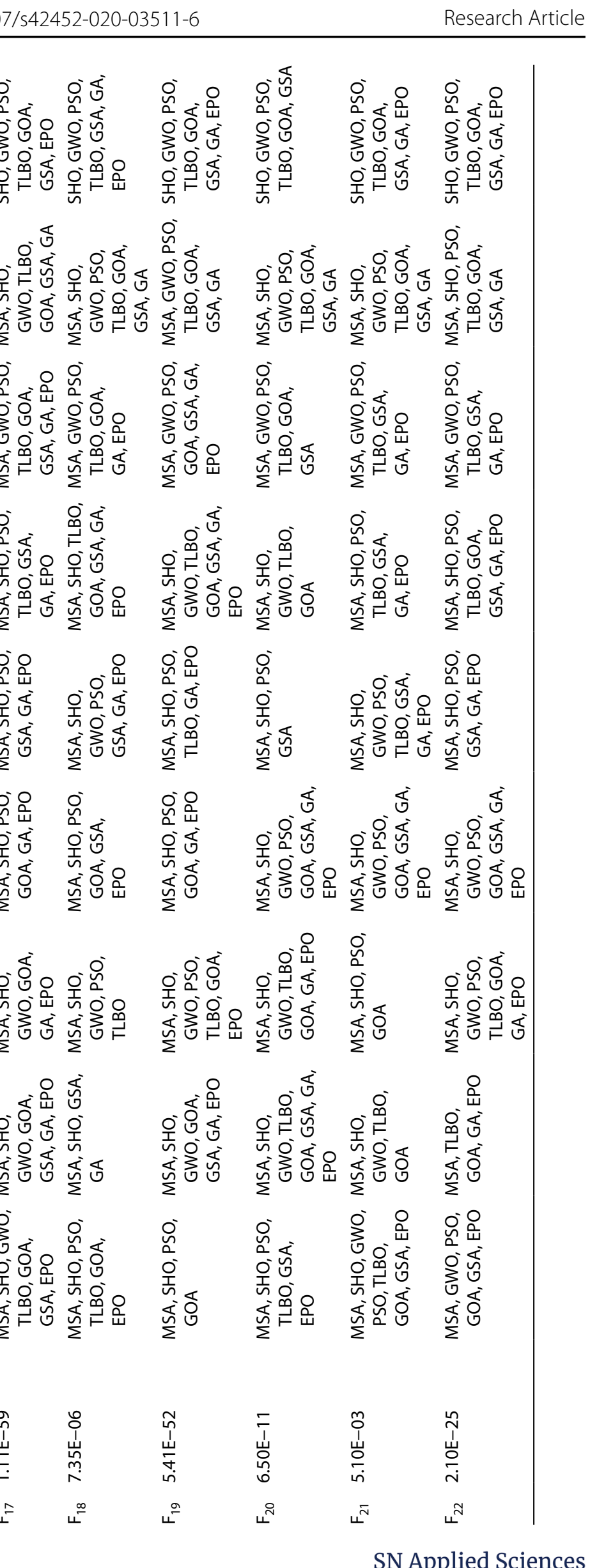

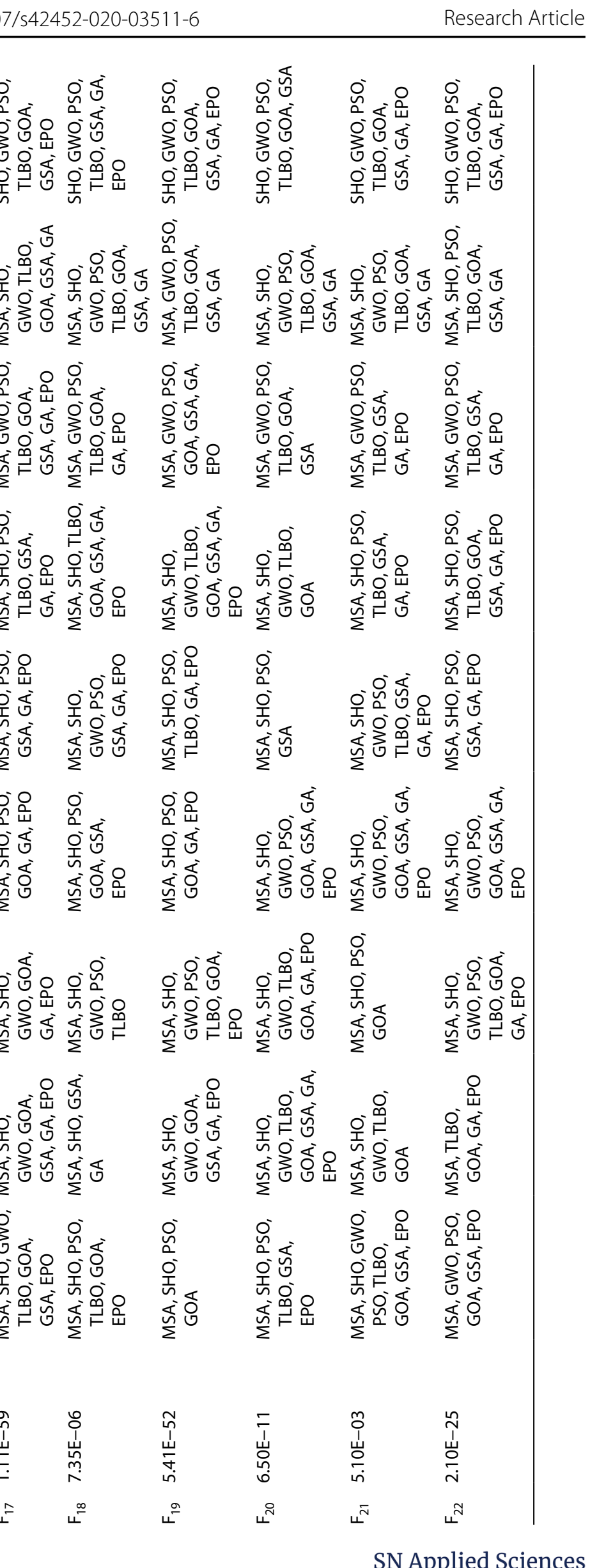

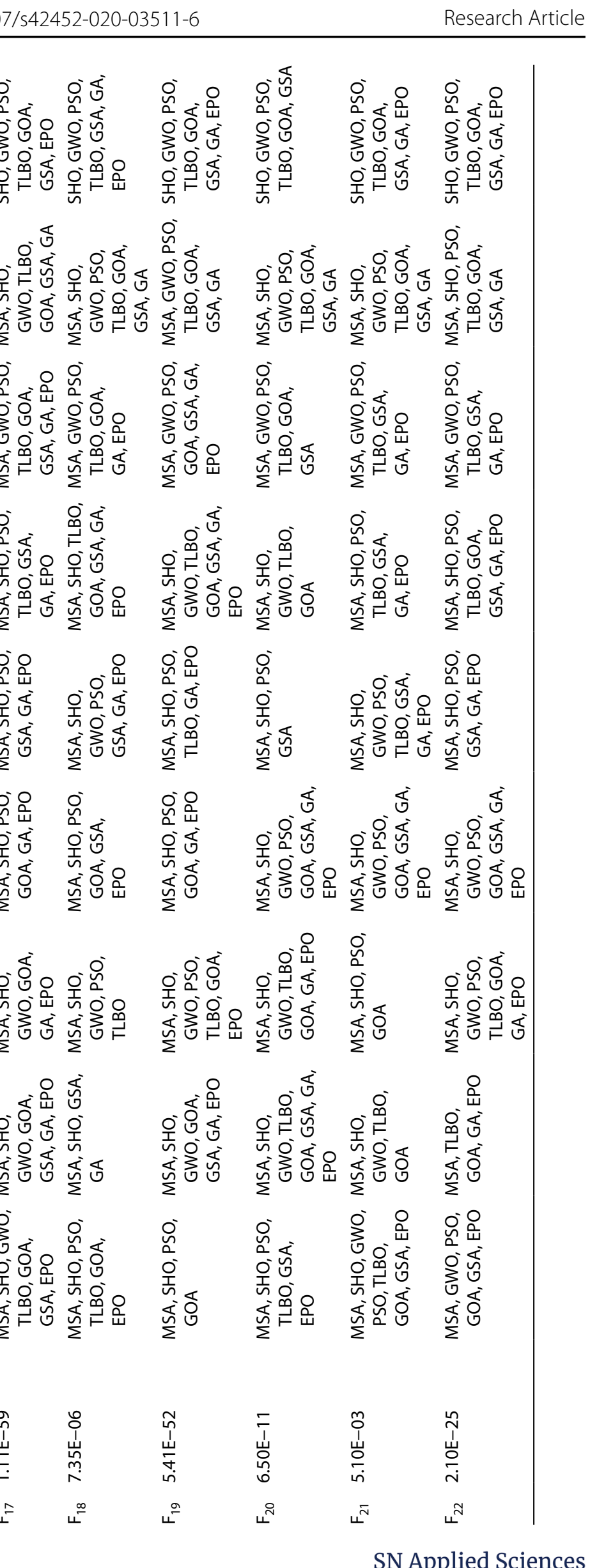

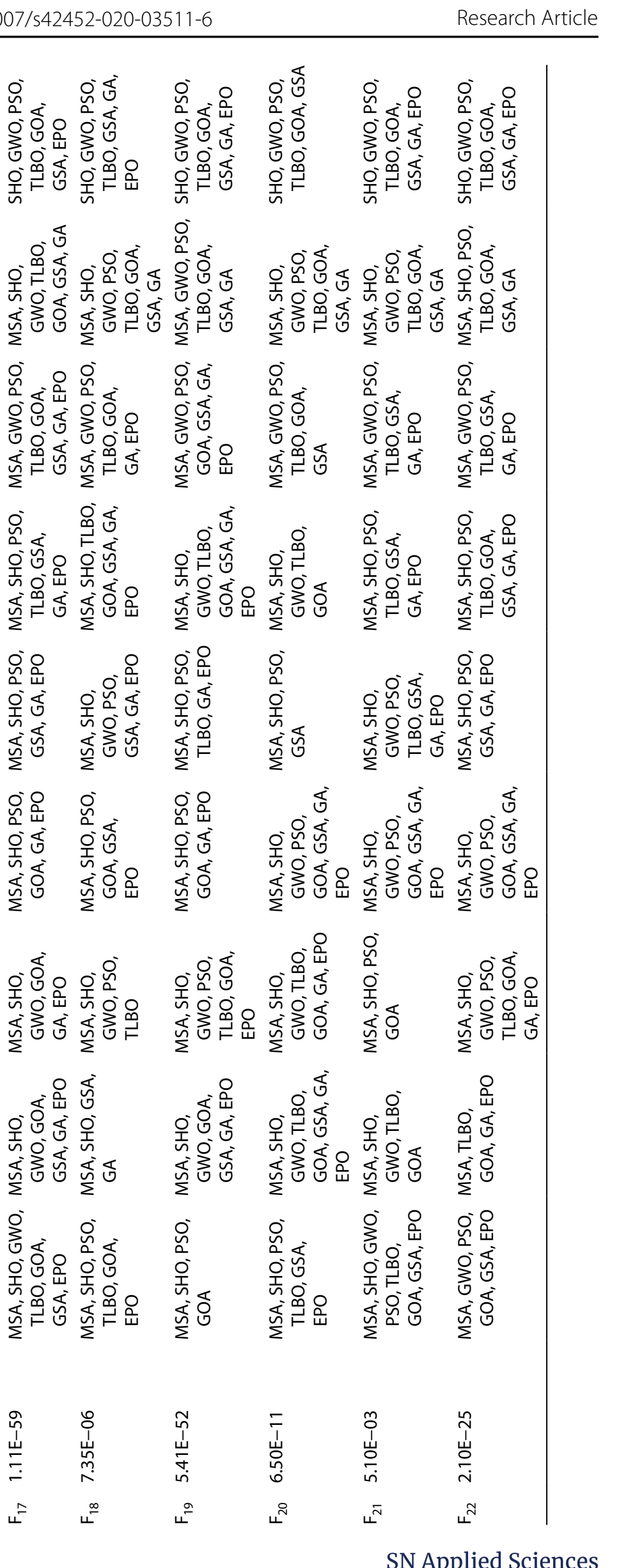

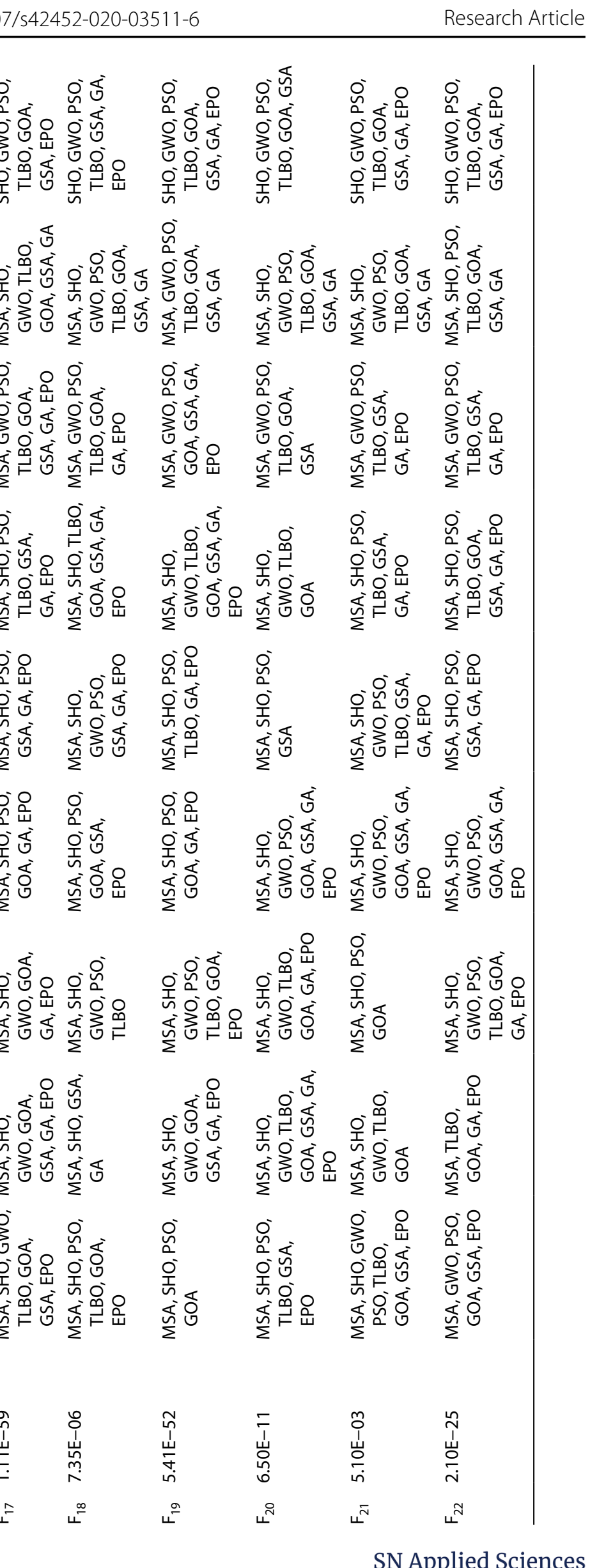

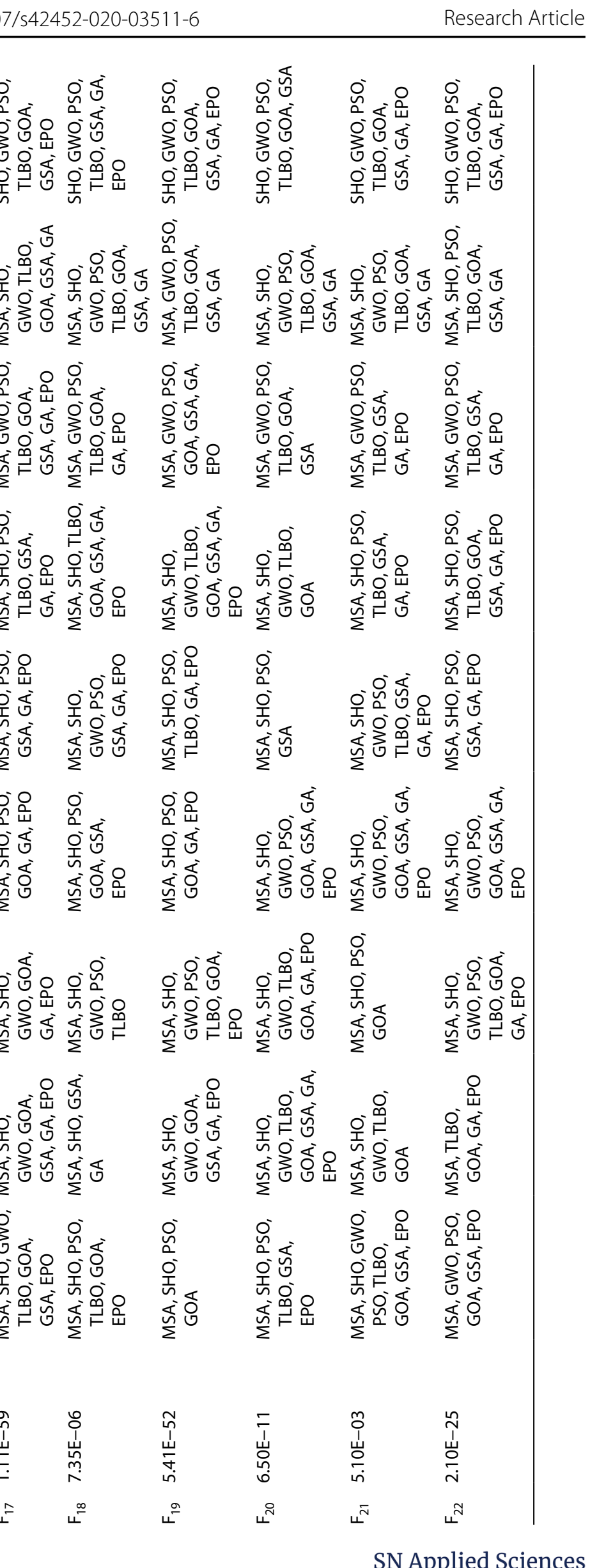

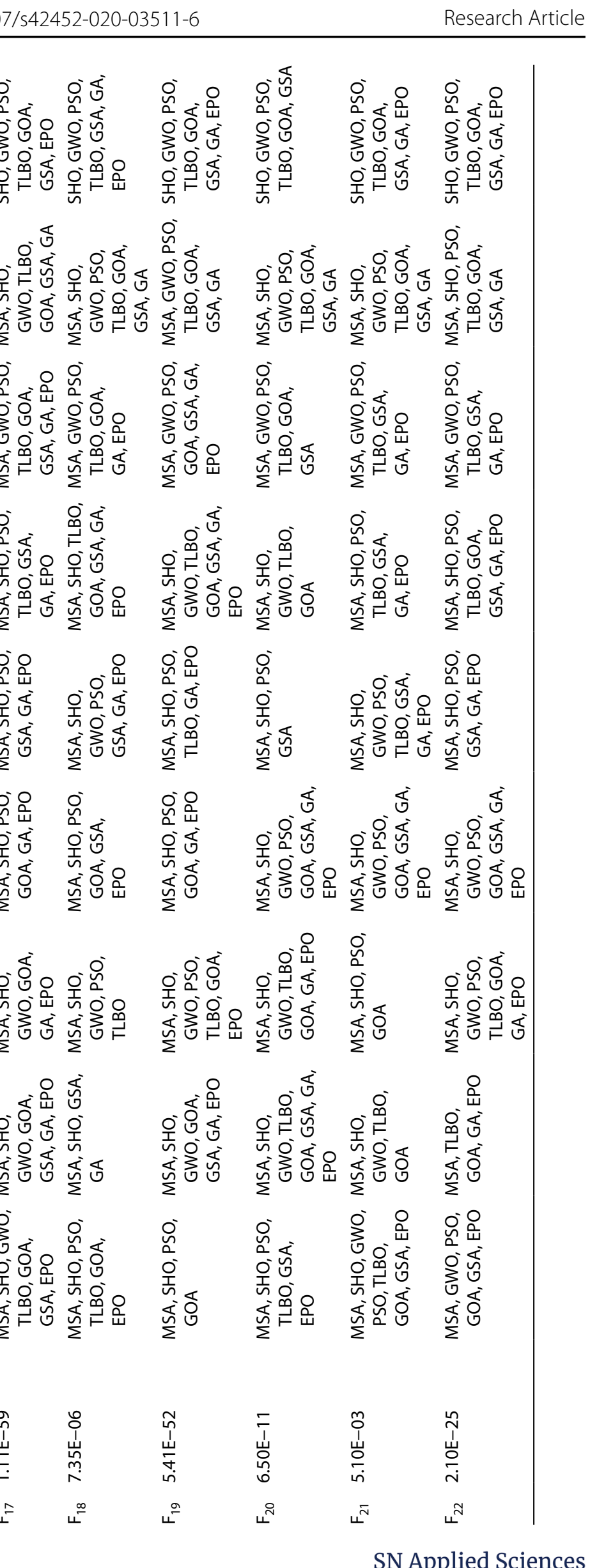

a

$$
\text { . }
$$




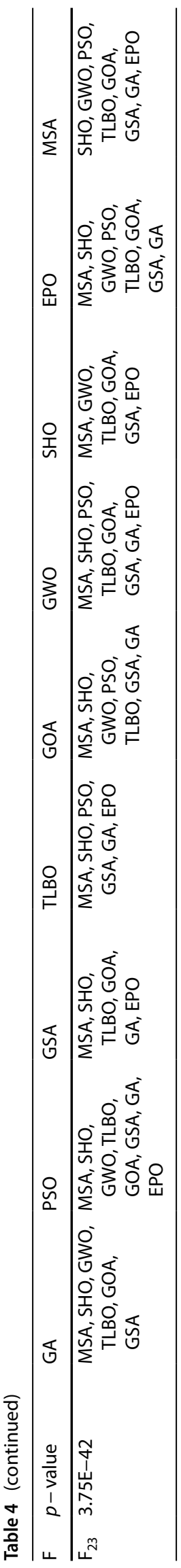

comparison with GA, PSO, GSA, TLBO, GWO, GOA, SHO and $E P O$, in all cases MSA produces near-optimal solutions.

For future works, there are several ideas that is suggested by the authors for study. As an interesting future contribution, one can develop a binary version of MSA. In addition, MSA can be applied to solve many-objective real-life optimization as well as multi-objective problems.

\section{Compliance with ethical standards}

Conflict of interest The authors declare that they have no conflict of interest.

\section{Appendix}

See Tables 5, 6 and 7.

Table 5 Unimodal test functions

\begin{tabular}{ll}
\hline$[-100,100]^{m}$ & $F_{1}(x)=\sum_{i=1}^{m} x_{i}^{2}$ \\
\hline$[-10,10]^{m}$ & $F_{2}(x)=\sum_{i=1}^{m}\left|x_{i}\right|+\prod_{i=1}^{m}\left|x_{i}\right|$ \\
{$[-100,100]^{m}$} & $F_{3}(x)=\sum_{i=1}^{m}\left(\sum_{j=1}^{i} x_{i}\right)^{2}$ \\
{$[-100,100]^{m}$} & $F_{4}(x)=\max \left\{\left|x_{i}\right|, 1 \leq i \leq m\right\}$ \\
{$[-30,30]^{m}$} & $\left.F_{5}(x)=\sum_{i=1}^{m-1}\left[100\left(x_{i+1}-x_{i}^{2}\right)^{2}+\left(x_{i}-1\right)^{2}\right)\right]$ \\
{$[-100,100]^{m}$} & $F_{6}(x)=\sum_{i=1}^{m}\left(\left[x_{i}+0.5\right]\right)^{2}$ \\
{$[-1.28,1.28]^{m}$} & $F_{7}(x)=\sum_{i=1}^{m} i x_{i}^{4}+\operatorname{random}(0,1)$ \\
\hline
\end{tabular}


Table 6 Multimodal test functions

\begin{tabular}{ll}
\hline$[-500,500]^{m}$ & $F_{8}(x)=\sum_{i=1}^{m}-x_{i} \sin \left(\sqrt{\left|x_{i}\right|}\right)$ \\
\hline$[-5.12,5.12]^{m}$ & $F_{9}(x)=\sum_{i=1}^{m}\left[x_{i}^{2}-10 \cos \left(2 \pi x_{i}\right)+10\right]$ \\
{$[-32,32]^{m}$} & $F_{10}(x)=-20 \exp \left(-0.2 \sqrt{\frac{1}{m} \sum_{i=1}^{m} x_{i}^{2}}\right)-\exp \left(\frac{1}{m} \sum_{i=1}^{m} \cos \left(2 \pi x_{i}\right)\right)+20+e$ \\
{$[-600,600]^{m}$} & $F_{11}(x)=\frac{1}{4000} \sum_{i=1}^{m} x_{i}^{2}-\prod_{i=1}^{m} \cos \left(\frac{x_{i}}{\sqrt{i}}\right)+1$ \\
{$[-50,50]^{m}$} & $F_{12}(x)=\frac{\pi}{m}\left\{\begin{array}{l}\left.10 \sin \left(\pi y_{1}\right)+\sum_{i=1}^{m}\left(y_{i}-1\right)^{2}\left[1+10 \sin ^{2}\left(\pi y_{i+1}\right)\right]+\left(y_{n}-1\right)^{2}\right\}+\sum_{i=1}^{m} u\left(x_{i}, 10,100,4\right) \\
{[-50,50]^{m}}\end{array}\right.$ \\
$F_{13}(x)=0.1\left\{x_{i}, a, i, n\right)=\left\{\begin{array}{c}k\left(x_{i}-a\right)^{n} x_{i}>-a \\
0-a<x_{i}<a \\
k\left(-x_{i}-a\right)^{n} x_{i}<-a\end{array}\right.$ \\
\end{tabular}

Table 7 Multimodal test functions with fixed dimension

\begin{tabular}{ll}
\hline$[-65.53,65.53]^{2}$ & $F_{14}(x)=\left(\frac{1}{500}+\sum_{j=1}^{25} \frac{1}{j+\sum_{i=1}^{2}\left(x_{i}-a_{i j}\right)^{6}}\right)^{-1}$ \\
\hline$[-5,5]^{4}$ & $F_{15}(x)=\sum_{i=1}^{11}\left[a_{i}-\frac{x_{1}\left(b_{i}^{2}+b_{i} x_{2}\right)}{b_{i}^{2}+b_{i} x_{3}+x_{4}}\right]^{2}$ \\
{$[-5,5]^{2}$} & $F_{16}(x)=4 x_{1}^{2}-2.1 x_{1}^{4}+\frac{1}{3} x_{1}^{6}+x_{1} x_{2}-4 x_{2}^{2}+4 x_{2}^{4}$ \\
{$[-5,10] \times[0,15]$} & $F_{17}(x)=\left(x_{2}-\frac{5.1}{4 \pi^{2}} x_{1}^{2}+\frac{5}{\pi} x_{1}-6\right)^{2}+10\left(1-\frac{1}{8 \pi}\right) \cos x_{1}+10$ \\
{$[-5,5]^{2}$} & $F_{18}(x)=\left[1+\left(x_{1}+x_{2}+1\right)^{2}\left(19-14 x_{1}+3 x_{1}^{2}-14 x_{2}+6 x_{1} x_{2}+3 x_{2}^{2}\right)\right]$ \\
{$[0,1]^{3}$} & $\times\left[30+\left(2 x_{1}-3 x_{2}\right)^{2} \times\left(18-32 x_{1}+12 x_{1}^{2}+48 x_{2}-36 x_{1} x_{2}+27 x_{2}^{2}\right)\right]$ \\
{$[0,1]^{6}$} & $F_{19}(x)=-\sum_{i=1}^{4} c_{i} \exp \left(-\sum_{j=1}^{3} a_{i j}\left(x_{j}-P_{i j}\right)^{2}\right)$ \\
{$[0,10]^{4}$} & $F_{20}(x)=-\sum_{i=1}^{4} c_{i} \exp \left(-\sum_{j=1}^{6} a_{i j}\left(x_{j}-P_{i j}\right)^{2}\right)$ \\
{$[0,10]^{4}$} & $F_{22}(x)=-\sum_{i=1}^{5}\left[\left(x-a_{i}\right)\left(x-a_{i}\right)^{T}+6 c_{i}\right]^{-1}$ \\
{$[0,10]^{4}$} & $F_{23}(x)=-\sum_{i=1}^{10}\left[\left(x-a_{i}\right)\left(x-a_{i}\right)^{T}+6 c_{i}\right]^{-1}$ \\
\hline
\end{tabular}




\section{References}

1. Bertsekas DP (1997) Nonlinear programming. J Oper Res Soc 48:334-334

2. Ruszczynski A (2011) Nonlinear optimization. Princeton University Press, Princeton

3. Luenberger DG, Ye Y (2008) Linear and nonlinear programming. International series in operations research \& management science. Springer, New York

4. Dehghani M, Mardaneh M, Malik OP, NouraeiPour SM (2019) DTO: Donkey Theorem Optimization. In: 2019 27th Iranian Conference on Electrical Engineering (ICEE), 2019, pp 1855-1859

5. Afshar A, Haddad OB, Mariño MA, Adams B (2007) Honey-bee mating optimization (HBMO) algorithm for optimal reservoir operation. J Franklin Inst 344:452-462

6. Eusuff MM, Lansey KE (2003) Optimization of water distribution network design using the shuffled frog leaping algorithm. J Water Res Plan Manag 129:210-225

7. Oftadeh R, Mahjoob M, Shariatpanahi M (2010) A novel metaheuristic optimization algorithm inspired by group hunting of animals: hunting search. Comput Math Appl 60:2087-2098

8. Dorigo M, Stützle T (2019) Ant colony optimization: overview and recent advances. In: Handbook of metaheuristics, Springer, Berlin, pp 311-351

9. Kennedy J, Eberhart R (1942) Particle swarm optimization, proceeding of the IEEE International Conference on Neural Networks, Perth, Australia. IEEE Service Center, Piscataway, vol 1948

10. Tang K-S, Man K-F, Kwong S, He Q (1996) Genetic algorithms and their applications. IEEE Signal Process Mag 13:22-37

11. Storn R, Price K (1995) Differential evolution-a simple and efficient adaptive scheme for global optimization over continuous spaces [R]. ICSI, Berkeley

12. Beyer H-G, Schwefel H-P (2002) Evolution strategies-a comprehensive introduction. Nat Comput 1:3-52

13. Koza JR (1990) Genetic programming: a paradigm for genetically breeding populations of computer programs to solve problems: Stanford University, Department of Computer Science

14. Mirjalili S (2019) Biogeography-based optimisation. In: Evolutionary algorithms and neural networks, Springer, 2019, pp 57-72

15. Fogel LJ, Owens AJ, Walsh MJ (1966) Artificial intelligence through simulated evolution

16. Dehghani M, Montazeri Z, Dehghani A, Nouri N, Seifi A (2017) BSSA: Binary spring search algorithm. In: 2017 IEEE 4th International Conference on Knowledge-Based Engineering and Innovation (KBEI), 2017, pp 0220-0224

17. Dehghani M, Montazeri Z, Dehghani A, Seifi A (2017) Spring search algorithm: a new meta-heuristic optimization algorithm inspired by Hooke's law. In: 2017 IEEE 4th International Conference on Knowledge-Based Engineering and Innovation (KBEI), 2017, pp 0210-0214

18. Kirkpatrick S, Gelatt CD, Vecchi MP (1983) Optimization by simulated annealing. Science 220:671-680

19. Lee KS, Geem ZW (2005) A new meta-heuristic algorithm for continuous engineering optimization: harmony search theory and practice. Comput Methods Appl Mech Eng 194:3902-3933

20. Geem ZW, Kim JH, Loganathan GV (2001) A new heuristic optimization algorithm: harmony search. Simulation 76:60-68

21. Omran MG, Mahdavi M (2008) Global-best harmony search. Appl Math Comput 198:643-656

22. Mahdavi M, Fesanghary M, Damangir E (2007) An improved harmony search algorithm for solving optimization problems. Appl Math Comput 188:1567-1579
23. Dehghani M, Mardaneh M, Malik OP (2019) FOA:'following' optimization algorithm for solving power engineering optimization problems. J Oper Autom Power Eng 8:57-64

24. Dehghani M, Montazeri Z, Dehghani A, Malik OP (2020) GO: Group Optimization. Gazi Univ J Sci 33, 2020

25. Dehghani M, Montazeri Z, Malik OP (2019) DGO: dice game optimizer. Gazi Univ J Sci 32:871-882

26. Dehghani M, Montazeri Z, Malik OP, Al-Haddad K, Guerrero JM, Dhiman G (2020) A new methodology called dice game optimizer for capacitor placement in distribution systems. Электротехника и электромеханика, 2020

27. Dehghani M, Montazeri Z, Malik OP, Dhiman G, Kumar V (2019) BOSA: binary orientation search algorithm. Int J Innov Technol Explor Eng IJITEE 9:5306-5310

28. Dehghani M, Montazeri Z, Malik OP, Ehsanifar A, Dehghani A (2019) OSA: orientation search algorithm. Int J Ind Electron Control Optim 2:99-112

29. Mohammad D, Zeinab M, Malik OP, Givi H, Guerrero JM (2020) Shell game optimization: a novel game-based algorithm. Int J Intell Eng Syst 10, 2020

30. Rashedi E, Nezamabadi-Pour H, Saryazdi S (2009) GSA: a gravitational search algorithm. Inf Sci 179:2232-2248

31. Prampero PS, Attux R (2011) Magnetic particle swarm optimization. In: 2011 IEEE Symposium on Swarm Intelligence (SIS), 2011, pp 1-7

32. Rao RV, Savsani VJ, Vakharia D (2011) Teaching-learning-based optimization: a novel method for constrained mechanical design optimization problems. Comput Aided Des 43:303-315

33. Karaboga D, Basturk B (2008) On the performance of artificial bee colony $(A B C)$ algorithm. Appl Soft Comput 8:687-697

34. Mirjalili S, Mirjalili SM, Lewis A (2014) Grey wolf optimizer. Adv Eng Softw 69:46-61

35. Kaveh A, Mahdavi VR (2014) Colliding bodies optimization: a novel meta-heuristic method. Comput Struct 139:18-27

36. Hansen N (2009) Benchmarking a BI-population CMA-ES on the BBOB-2009 function testbed. In: Proceedings of the 11th Annual Conference Companion on Genetic and Evolutionary Computation Conference: Late Breaking Papers, 2009, pp 2389-2396

37. Wang G-G (2018) Moth search algorithm: a bio-inspired metaheuristic algorithm for global optimization problems. Mem Comput 10:151-164

38. Feng $\mathrm{Y}-\mathrm{H}$, Wang G-G (2018) Binary moth search algorithm for discounted 0-1 knapsack problem. IEEE Access 6:10708-10719

39. Wang G-G, Deb S, Cui Z (2019) Monarch butterfly optimization. Neural Comput Appl 31:1995-2014

40. Wang G-G, Deb S, Zhao X, Cui Z (2018) A new monarch butterfly optimization with an improved crossover operator. Oper Res Int J 18:731-755

41. Wang G-G, Deb S, dos Santos Coelho L (2018) Earthworm optimisation algorithm: a bio-inspired metaheuristic algorithm for global optimisation problems. IJBIC 12:1-22

42. Wang G-G, Deb S, Coelho LDS (2015) Elephant herding optimization. In: 2015 3rd International Symposium on Computational and Business Intelligence (ISCBI), 2015, pp 1-5

43. Li W, Wang G-G, Alavi AH (2020) Learning-based elephant herding optimization algorithm for solving numerical optimization problems. Knowl-Based Syst 105675

44. Wang G-G, Tan Y (2017) Improving metaheuristic algorithms with information feedback models. IEEE Trans Cybern 49:542-555

45. Yi J-H, Deb S, Dong J, Alavi AH, Wang G-G (2018) An improved NSGA-III algorithm with adaptive mutation operator for Big Data optimization problems. Fut Gener Comput Syst 88:571-585

46. Yi J-H, Xing L-N, Wang G-G, Dong J, Vasilakos AV, Alavi AH et al (2020) Behavior of crossover operators in NSGA-III for large-scale optimization problems. Inf Sci 509:470-487 
47. Gu Z-M, Wang G-G (2020) Improving NSGA-III algorithms with information feedback models for large-scale many-objective optimization. Fut Gener Comput Syst 107:49-69

48. Zhang Y, Wang G-G, Li K, Yeh W-C, Jian M, Dong J (2020) Enhancing MOEA/D with information feedback models for large-scale many-objective optimization. Information Sci

49. Wang G-G, Cai X, Cui Z, Min G, Chen J (2017) High performance computing for cyber physical social systems by using evolutionary multi-objective optimization algorithm. IEEE Transactions on Emerging Topics in Computing

50. Wang H, Yi J-H (2018) An improved optimization method based on krill herd and artificial bee colony with information exchange. Mem Comput 10:177-198

51. Tarasewich P, McMullen PR (2002) Swarm intelligence: power in numbers. Commun ACM 45:62-67

52. Mahesh KM, Renjit JA (2018) Evolutionary intelligence for brain tumor recognition from MRI images: a critical study and review. Evolutionary Intelligence, pp 1-12

53. Dehghani M, Montazeri Z, Malik O (2019) Energy commitment: a planning of energy carrier based on energy consumption, Электротехника и электромеханика,

54. Montazeri Z, Niknam T (2018) Optimal utilization of electrical energy from power plants based on final energy consumption using gravitational search algorithm, p 4, 2018-08-17 2018

55. Dehbozorgi S, Ehsanifar A, Montazeri Z, Dehghani M, Seifi A (2017) Line loss reduction and voltage profile improvement in radial distribution networks using battery energy storage system. In: 2017 IEEE 4th International Conference on KnowledgeBased Engineering and Innovation (KBEI), 2017, pp 0215-0219

56. Dehghani M, Mardaneh M, Montazeri Z, Ehsanifar A, Ebadi M, Grechko O (2018) Spring search algorithm for simultaneous placement of distributed generation and capacitors, Электротехника и электромеханика

57. Dehghani M, Montazeri Z, Malik O (2020) Optimal sizing and placement of capacitor banks and distributed generation in distribution systems using spring search algorithm. International Journal of Emerging Electric Power Systems, vol 21, 2020

58. Ehsanifar A, Dehghani M, Allahbakhshi M (2017) Calculating the leakage inductance for transformer inter-turn fault detection using finite element method. In Iranian Conference on Electrical Engineering (ICEE) 2017:1372-1377

59. Dehghani M, Montazeri Z, Ehsanifar A, Seifi A, Ebadi M, Grechko $O$ (2018) Planning of energy carriers based on final energy consumption using dynamic programming and particle swarm optimization, Электротехника и электромеханика

60. Montazeri Z, Niknam T (2017) Energy carriers management based on energy consumption. In: 2017 IEEE 4th International Conference on Knowledge-Based Engineering and Innovation (KBEI), 2017, pp 0539-0543

61. Halliday D, Resnick R, Walker J (2013) Fundamentals of physics. Wiley, Hoboken

62. Yao X, Liu Y, Lin G (1999) Evolutionary programming made faster. Evol Comput IEEE Trans 3:82-102

63. Lynn N, Suganthan PN (2015) Heterogeneous comprehensive learning particle swarm optimization with enhanced exploration and exploitation. Swarm Evol Comput 24:11-24

64. Digalakis JG, Margaritis KG (2001) On benchmarking functions for genetic algorithms. Int J Comput Math 77:481-506

65. Wang G-G, Gandomi AH, Yang X-S, Alavi AH (2014) A novel improved accelerated particle swarm optimization algorithm for global numerical optimization. Engineering Computations, 2014

66. Yang X-S (2010) Firefly algorithm, stochastic test functions and design optimisation, arXiv:1003.1409

67. Mirjalili S (2019) Genetic Algorithm. In: Evolutionary Algorithms and Neural Networks, Springer, 2019, pp 43-55

68. Mirjalili S (2019) Particle Swarm Optimisation. In: Evolutionary Algorithms and Neural Networks, Springer, 2019, pp 15-31

69. Saremi S, Mirjalili S, Lewis A (2017) Grasshopper optimisation algorithm: theory and application. Adv Eng Softw 105:30-47

70. Dhiman G, Kumar V (2017) Spotted hyena optimizer: a novel bio-inspired based metaheuristic technique for engineering applications. Adv Eng Softw 114:48-70

71. Dhiman G, Kumar V (2018) emperor penguin optimizer: a bioinspired algorithm for engineering problems. Knowledge-Based Systems

Publisher's Note Springer Nature remains neutral with regard to jurisdictional claims in published maps and institutional affiliations. 